
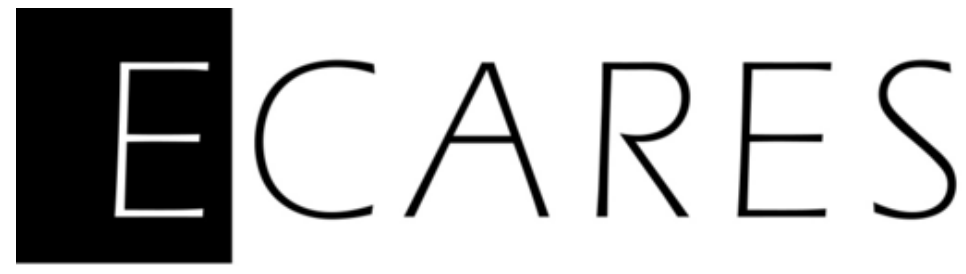

\title{
Informational Shocks and Street-food Safety: A Field Study in Urban India
}

\author{
Giammarco Daniele \\ Bocconi University Milan \\ Sulagna Mookerjee \\ Georgetown University Qatar \\ Denni Tommasi \\ ECARES, Université libre de Bruxelles
}

July 2018

ECARES working paper 2018-20

ECARES

ULB - CP 114/04

50, F.D. Roosevelt Ave., B-1050 Brussels BELGIUM

www.ecares.org 


\title{
Informational shocks and street-food safety:
}

\author{
A field study in urban India
}

\author{
Gianmarco Daniele ${ }^{1}$, Sulagna Mookerjee ${ }^{2}$, and Denni Tommasi*3 \\ ${ }^{1}$ Bocconi University \\ ${ }^{2}$ Georgetown University Qatar \\ ${ }^{3}$ ECARES, Université libre de Bruxelles
}

July 31, 2018

\begin{abstract}
Street-food safety is a public health concern in several developing countries. We investigate whether improvements in food safety can be achieved by providing information to vendors in the form of a training. Among randomly assigned groups of street-food vendors in urban Kolkata, India, we find large improvements in knowledge and awareness, but little changes in their observed behaviors. We provide suggestive evidence that a combination of both lack of demand for food safety and perceived high costs of hygiene practices for vendors, are likely to drive the results. We conclude that information is not the key constraint in this context.
\end{abstract}

JEL Codes: L2, O17, O33

Keywords: Food Safety, Public Health, Street-Food, Hawkers, Trainings, RCT, Informal Sector.

\footnotetext{
* Daniele: gianmarco.daniele@unibocconi.it; Mookerjee: sulagna.mookerjee@georgetown.edu and Tommasi: dtommasi@ulb.ac.be. We are extremely grateful to InnoAid for the support to conduct this research project, in particular the President Marie Louise Pollman-Larsen and the Project Manager Matias Pollmann-Larsen. This project was funded by CISU (Civil Society in Development), which is financed by The Danish Ministry of Foreign Affairs. The experiment has been registered with AEA RCT registry with ID-0000750. The project was shortlisted for the WAF Award 2015. IRB approval was obtained from Georgetown University. We thank the program teams of Joygopalpur Gram Vikash Kendra (JGVK) and Gana Unnayan Parshad (GUP), in particular the Project Leaders Sudipta Barman and Sudipta Moitra, project coordinators Anindya Basu and Ashis Saha, our Research Assistant Parswati Dasgupta, and the entire field team, for their collaboration during the implementation of the project and data collection. We are indebted to Agnese Carrera, Luca Coraggio, Giorgia Moretta, Valentina Pretolani and Marie Rueskov Grif, for outstanding research assistance and countless contributions during several phases of the project. We thank Gani Aldashev, Samson Alva, Tommaso Aquilante, Anik Ashraf, Jean Marie Baland, Stefan Bergheimer, Ilaria D’Angelis, Georg Kirchsteiger, Luca Livio, Giovanna Marcolongo, Andreas Menzel, Pauline Rossi, Priyanka Sarda, Glenn Sheriff, Lorenzo Trimarchi, Marcella Veronesi, and seminar participants at Boston College, Paris School of Economics, Université libre de Bruxelles, University of Copenhagen, University of Nottingham, and University of Rochester. We have no relevant or material financial interests that relate to the research described in this paper. All errors are our own.
} 


\section{Introduction}

The Food and Agricultural Organization (FAO) and the World Health Organization (WHO) regularly report that the consumption of unsafe street food affects millions of people all over the world (FAO and WHO, 2002; WHO, 2008a). Since street food accounts for a significant proportion of the daily urban food consumption of 2.5 billion consumers (FAO, 2007), having a more reliable and safer food supply chain remains one of the major public health concerns of many governments (FAO, 2009; Bhowmik, 2012). Several factors contribute to this status quo. First, vendors often lack access to basic infrastructures like clean water (Duflo et al., 2012). Second, this is an informal sector plagued by uncertainty, which lowers the incentives for vendors to make the necessary investments to improve the quality of their business (FAO, 2013). Finally, street vending is an occupation that requires little start-up capital, and therefore draws a large section of the urban poor who lack awareness and adequate training in safe food handling methods, further exacerbating the problem (NCEUS, 2007; World Bank, 2013).

In this paper, we focus on the last factor and seek to understand whether a training aimed at improving vendors' awareness about food safety, can reduce street-food safety hazards. The simple underlying hypothesis is that such a training reduces the costs of awareness and allows (in principle) the vendors to sell to consumers a more desirable good (or service). The project was undertaken in Kolkata, India, from March 2015 to July 2016, with the logistic support of Innoaid, a Danish-based Nongovernment Organization (NGO). ${ }^{1}$ We collected a sample of 681 street-food vendors, spread out in different areas of the city, and grouped them into 74 blocks of roughly 10 vendors each. ${ }^{2}$ We then randomly allocated a fraction of the blocks of vendors to receive a training program. The training consisted of 3 workshops and 3 follow-ups, organized over 10 consecutive weeks, and had two main objectives: first, to enhance vendors' awareness of health risks related to food vending, and second, to develop their capacity to make the necessary improvements in food safety practices. Further, half of the vendors who were assigned to the training also received promotional material, specifically tailored posters, napkins and certificates, allowing them to advertise to customers their participation in the program.

\footnotetext{
${ }^{1}$ Innoaid is active in addressing development challenges supported by academic collaborations. They started working on street-food vendors in Kolkata in 2008. Besides Innoaid, the project was implemented jointly with two local organizations active in promoting sustainable development for the poor and marginalized communities: Joygopalpur Gram Vikash Kendra (JGVK) and Gana Unnayan Parshad (GUP). For more details on Innoaid and its partners, see the Online Appendix and: http://www . innoaid.org/partners/existing-partners/.

${ }^{2}$ We explain in more details in Section 2.3 what we mean by "block" of vendors.
} 
At the beginning and at the end of the study, we collected data on vendors' socio-economic characteristics, as well as their awareness about food safety and health threats, actions taken, and business practices. Additionally, we monitored vendors' actual behavior between the baseline and the endline surveys for a total of 6 data points for each vendor. The direct monitoring of vendors' daily behaviors at their kiosks allows us to have a more comprehensive and accurate evaluation of their practices without relying exclusively on self-reported information. Moreover, at each point of the data collection and training, the take-up rate is always above 70\%. Altogether this makes our study novel also for the degree of accuracy of the data collected about street-vendors. Hence our setup allows to identify the effect of the program in a simple difference-in-difference framework, comparing outcomes for vendors in treatment and control groups before and after the workshops. It is crucial to point out that our results are not going to be driven by spillover effects because we collected precise information also about each vendor's network on the street and hence we can control for it. We elaborate on this in the Data section.

Our design has a major advantage from the point of view of the identification. Indeed, given that (i) Eligibility for the training is randomly allocated, (ii) The participation is voluntary, and (iii) There is no mandated penalty for non-compliance to food-safety practices, we can identify the effect of increased awareness on vendors' behavior such that it is not confounded by the fear of punishment. This would not be the case, for instance, if one were evaluating a government-designed food hygiene monitoring program. In this case, the vendors' observed behavior could be driven by both the improved awareness and the threat of sanctions in case of non-compliance, with the two being difficult to disentangle. ${ }^{3}$ In our case, any effect of the training provides evidence towards a potential scope of self-regulation by the vendors. ${ }^{4}$ This is informative to a policy-maker, because it would make the case for the efficacy of such an intervention due to its low cost of implementation. Indeed, fines and sanctions may provide stronger incentives for vendors to comply with higher foodsafety practices, but it would likely be a much more expensive intervention, especially in a weak and complex institutional environment. ${ }^{5}$

\footnotetext{
${ }^{3}$ In this regard, we relate to the social-dilemma literature on the effectiveness of rewards versus punishments (e.g. Sigmund et al. (2001), Van Lange et al. (2014)).

4 "Self-regulation" refers to the set of actions undertaken by the private sector to regulate itself. This might arise for several reasons such as: (i) self-interest, e.g. a firm deciding to sell a "green" product because consumers are willing to pay for it; (ii) to enhance ethical beliefs (Baron, 2010); (iii) to deter public regulation (Maxwell et al., 2000; Lyon and Maxwell, 2004) or boycotting (Baron, 2009; Baron and Diermeier, 2007).

${ }^{5}$ Recent experiments document that such threats may not always work positively (e.g. Casaburi and Macchiavello (2015)). Nevertheless, these findings support our argument that sanctions would prevent us to identify the (pure) effect of increased awareness on vendors' behavior such that it is not confounded by other effects. For our specific context, details on the street food sector in Kolkata are provided in the Background section.
} 
The first set of results is twofold. First, we find a substantial effect of the training on vendors' awareness, knowledge of food safety hazards and self-reported safety behaviors. For instance, vendors in the treatment groups are $8 \%$ more likely to be able to articulate some measures of proper food hygiene, $3 \%$ more likely to know some practices for personal hygiene, $8 \%$ more likely to articulate what potential contaminants of food are, and 10\% more likely to know how to handle common utensils hygienically. In terms of claimed actions taken, they are on average more likely to engage in discussions about safe-food practices with other vendors (20\%), to gather further information about these practices (13\%), and to attempt improving the water distribution and garbage disposal facilities in their stalls (23\%). Second, concerning actual food safety behaviors (as measured by the external monitors), we assign vendors scores based on several observed practices, and map these scores into 4 indexes: Facilities, which captures basic cleanliness and facilities around the stall, and is applicable to all vendors; Handling which captures food handling, and is only relevant for vendors preparing food in the stall; Customers which relates to customer service, and it is applicable only to vendors who have facilities for customers to eat within the stall premises; Total, which is the average of all indexes. A vendor exhibiting perfect behavior on all dimensions of an index would get a score of $100 \%$. We observe that, despite the significant changes in awareness and claimed actions taken, there is a limited significant change in actual food safety behaviors, with the Facilities index increasing by only $3.9 \%$ after the third workshop, and the Total index by only $2.7 \%$, whereas the rest of the indexes are not significantly affected.

Given the complexity of the sector, there are several reasons that might explain why behavioral improvements in food safety are difficult to undertake. The simplest one may be that vendors lack the basic necessary incentives because, even if they changed their behavior, they know the quality of their goods would be difficult to observe in practice, and hence they would not be able to retain a larger surplus from the consumers. This would be the case if food safety improvements take place during processes which are not visible to customers, as in the case of some food storage and preservation processes. Since one treatment arm is given free tools to advertise participation to the program, we are able to test directly whether food safety improvements are prevented because they might go unnoticed by consumers. With respect to this dimension, we do not find a significantly different impact for this group of vendors compared to the basic treatment. This implies that "advertisement" of hygiene practices (or lack of) is not a crucial factor, and therefore can be rejected as possible explanation. 
Another possibility might be related to the main underlying assumptions behind our intervention. We provide some (at least partial) tests against them, which in turn may help providing some concrete explanations for our findings. Concerning the supply side of the market, our implicit assumption is that an informational training about food safety is going to reduce the costs to produce safer goods. However, the production of such goods might be difficult because, besides lacking awareness about food safety, vendors are also constrained by the lack of several other costly facilities, such as clean water, waste disposal and electricity. This channel could be tested by randomizing a monetary compensation (cash or in-kind) to vendors. However, since we deal with a complex sector characterized by widespread extortion suffered by street vendors, monetary incentives are difficult to test in our context. ${ }^{6}$ Following the same idea, we collect instead direct information about individual perceived costs of improving food safety (pre and post intervention), and find that the training does not decrease these costs. We take the latter result as indirect evidence that the perceived costs of making behavioral improvements are high and were not lowered by the training. Concerning the demand side of the market, our implicit assumption is that consumers have a larger marginal willingness to pay for safer food. However, consumers might be accustomed to the current street-food hygienic standards, and hence their marginal willingness to pay might not be that different. Ideally we could test this either by collecting these information directly from customers, or by randomizing a training to them. However, this was not feasible in our context, but in line with this idea, we show that vendors actually improving food safety behaviors do not benefit more in terms of higher revenues or profits, which supports this idea. All in all, our findings imply that a training is not sufficient to foster substantial changes in food-safety, suggesting that information alone is not the key constraint in this sector.

The paper contributes to a flourishing literature investigating the role of trainings offered to micro-entrepreneurs in developing countries. While they mostly focus on improving business practices to foster profitability and employment (Karlan and Valdivia, 2011; Mano et al., 2012; De Mel et al., 2014; Argent et al., 2014; Valdivia, 2015; Brooks et al., 2018), our main goal is to reduce a negative externality, food safety hazards, through an informational training. In this regard, we relate to information experiments aimed at improving health outcomes. Previous studies randomized information on the importance of wearing eye glasses (Ma et al., 2013), on how to avoid intestinal

\footnotetext{
${ }^{6}$ This is confirmed both by the information we collected at baseline and also by InnoAid's local partners, who were highly skeptical about providing monetary incentives to street vendors. More details in the background section.
} 
worm infections (Meredith et al., 2013) or prevent HIV (Duflo et al., 2015; Dupas, 2011), and to access to family planning sessions (Ashraf et al., 2014). In a recent review of this literature, Dupas and Miguel (2017) state that "Information is necessary but often not sufficient to generate take-up" (page 41): similar conclusions can be drawn from our experiment. The only previous study that we are aware of that deals with retailers is Banerjee et al. (2015), in which they provide information and financial incentives (higher markups) to retailers selling a specific type of salt aimed at reducing anemia. Differently from this latter paper, we do not rely on financial incentives because they are difficult to implement for the reasons we explained before.

Closely related to our paper, small-scale studies run by microbiologists show mixed results about the effectiveness of trainings aimed at improving food safety among street vendors (e.g. Choudhury et al. (2011); Soon et al. (2012); Abushelaibi et al. (2015); da Cunha et al. (2014)). With respect to this literature, we differentiate upon several dimensions: i) We provide an economic framework to understand vendors' behaviors and test different explanations behind our findings; ii) We base our inferences on a larger sample of vendors; iii) We provide a novel approach to assess and measure food safety standards, based on a multitude of information collected on multiple observations, which could be replicated in similar contexts; (iv) We collected precise information about each vendor's network on the street to account for possible spillover effects and spread of information contained in the workshops; (v) Finally, our results also allow measuring how lasting is the informational shock provided by the workshop. With respect to this last point, we find that vendors' awareness and knowledge of food safety measures are still present five months after the last training. This is despite the fact that the training was substantially shorter (up to six meetings) than other studies focused on business practices.

Lastly, our study has also a strong policy relevance because the Indian government is currently undertaking a process of formalization of street vendors. Indeed, the Parliament of India enacted to regulate street vendors in public areas and passed a National Act for Urban Street Vendors ("Protection of Livelihood and Regulation of Street Vending") in March 2014. The aim of the Act is to regulate the unorganized street vending sector, providing specific zones to the street vendors, a proper license to run their business and recommendations concerning health and hygienic standards (NPUSV, 2009). The implementation of this policy has been so far limited to few urban areas, and, as of 2018, Kolkata is not among them yet. Therefore, much of the business still remains informal throughout India. This makes the results of our study very timely and relevant for the policy-makers 
who need to deal with the practical implementation of the National Act. This is true not only for Kolkata, but also for the rest of India, as well as for similar countries in South-East Asia wishing to undertake a similar path.

The remainder of this paper is organized as follows. In Section 2 we briefly describe the context of our study and the design of the experiment. In Section 3, we present our data. We describe our empirical strategy and report our results in Section 4. We conclude in Section 5.

\section{Background, Design and Intervention}

\subsection{Background on Street Vendors}

Street vending is the activity of selling goods and services in the streets without having a permanent built-up structure (Wongtada, 2014). This is an important and growing source of employment in developing countries, especially for the urban poor, as it does not require specialized skills or a large start-up capital (FAO, 2013). Street vending is mostly conducted in the informal sector, as local authorities are unable (and/or unwilling) to regulate this sector, also because they often lack sufficient resources to establish and enforce a license system (Bhowmik, 2012). On their side, vendors are often criticized for providing low quality goods, creating congestion and safety risks (Bromley, 2000). This precarious position and highly uncertain environment make them ideal victims for harassment such as evictions, confiscation of merchandise, and demands for extortion (Bhowmik, 2012). Nevertheless, street-vendors around the world are considered a successful example of collective actors in the society, as they are often organized in unions and informal groups promoting their collective interests (Saha, 2016).

Among street vendors, food sellers represent the most visible group as they provide affordable and nutritional food to millions of urban consumers every day, especially to low- and middle- income consumers with limited time and means for shopping and cooking (FAO, 2007). However, as acknowledged by international organizations, street-food might represent a health threat both because vendors lack access to basic infrastructures and because they often lack expertise in food handling methods (WHO, 2008a; FAO, 2009, 2013). This has been documented in several recent studies, among others, in Ghana (Mensah et al., 2002), South Africa (Lues et al., 2006), Haiti (Samapundo et al., 2015), Brazil (Cortese et al., 2016) and Vietnam (Samapundo et al., 2016), showing 
that food safety knowledge is limited among street vendors. Such food safety hazards might lead to water-borne, vector-borne and food-borne diseases (Rane, 2011), which are strongly linked to mortality from diarrhea, causing approximately 2.2 million deaths annually (WHO, 2008b). Importantly, the above mentioned studies also point out that most health hazards may be prevented simply through careful food handling.

Our study is based in Kolkata, which is the third largest urban agglomeration in India, with a population of about 14 million inhabitants, and is the main business, commercial and financial hub of Eastern India. The most recent estimates suggest that there are 300,000 street vendors in greater Kolkata, and approximately half of them are street-food vendors (NCEUS, 2009), selling rich, diverse and affordable food to millions of customers every day. Similarly to other urban areas, Kolkata is not exempt from public health issues generated by street-food vending. One of the first documented research on this city is a study by the All Indian Institute of Hygiene and Public Health (AIIH and PH), with support from FAO (Chakravarty and Canet, 1996), which has shown that food safety hazards are prevalent in Kolkata due to limited food hygiene awareness, unclean environments, working practices and food adulteration. More recent case studies report that $47 \%$ samples of water used by street-food vendors were contaminated (Walvekar, 2017). Importantly, they highlight that the water was safe at the source, but became contaminated through poor handling practices.

\subsection{A simple model of vendors' behavior under uncertainty}

Given the above description of the context, we wish to formalize vendors' behavior within a simple model of profit maximization under uncertainty. Assume there is a continuum of street-food vendors operating in a market of differentiated goods. For simplicity, vendors have to choose whether to produce a good of quality $H$ (igh) or $L$ (ow).

In order to produce $L$, costs and revenues are known and the expected profits are set to $E\left[\pi_{L}\right]=$ 1 as benchmark. In order to produce $H$, vendors face uncertainty about both costs and revenues. For each vendor, the expected profits are $E\left[\pi_{H}\right]=E[R-C]$, where, for simplicity, $C \sim N\left(\mu_{C}, \sigma_{C}^{2}\right)$ and $R \sim N\left(\mu_{R}, \sigma_{R}^{2}\right) \cdot{ }^{7}$ Assume further that $\sigma_{R}^{2} \perp \sigma_{C}^{2}$ and $E[R-C]=\mu_{R}-\mu_{C}>1$. The latter can be thought as consumers having a larger taste for $H$ over $L$ because it is more healthy and therefore yields higher utility. The random variable $C$ captures the ex-ante uncertainty about investing in

\footnotetext{
${ }^{7}$ Note that the assumption of normality is not crucial here. A more realistic assumption of, e.g., truncated normal would yield the same qualitative equilibrium condition, but at the cost of a much more tedious derivation.
} 
$H$. The uncertainty comes from two sources: (i) vendors may have different ("hard") costs of production and (ii) vendors' awareness about food quality, safety and its production, is a ("soft") costly information. In particular, a vendor with high awareness has less cost to produce $H$ than a vendor with low awareness, conditional on the same lack of basic infrastructure and costs on the street. $R$ captures the idea that vendors are uncertain about the consumers' willingness to pay for $H$ (which implies that vendors are uncertain about the aggregate demand). ${ }^{8}$ Uncertainty is further exacerbated by consumers finding difficult to detect whether a vendor is selling a good of quality $H$ or $L$.

A distinctive feature of our model is the assumption that vendors are risk adverse with respect to profits from the high-quality good, and they differ in the degree of risk aversion. Risk aversion is captured by the standard Arrow-Pratt measure of constant absolute risk-aversion (CARA), which is distributed over the interval $[0, x]$. Hence vendors producing $H$ have utility $U_{H}=-e^{-\lambda \pi_{H}}$ (versus a known $U_{L}=1$ ). The problem they solve can be restated as follows:

$$
\max \left\{\mu_{R}-\mu_{C}-\lambda \frac{\sigma_{R}^{2}+\sigma_{C}^{2}}{2}\right\}
$$

Vendors produce $H$ if $U_{H}>U_{L}$, that is, under the condition that:

$$
\lambda<\frac{2\left(\mu_{R}-\mu_{C}-1\right)}{\sigma_{R}^{2}+\sigma_{C}^{2}} .
$$

In the absence of an intervention in the market, the share of vendors producing $H$ can be represented by the colored area in Figure 1.

Inequality (2) leads us to formulate two simple (cheap) interventions and testable hypotheses to increase the expected utility of vendors to produce $H$ and hence to increase the share of high-quality food in the market.

Hypothesis 1. An informational training aimed at increasing awareness about food quality and safety, leads to (i) A decrease in the expected costs $\mu_{C}$ and costs uncertainty $\sigma_{C}^{2}$ to produce $H$, and (ii) An increase in the share of vendors producing $H$.

Hypothesis 2. Providing vendors with promotional material, specifically tailored posters, napkins and certificates, allowing them to advertise to customers their participation in the informational training

\footnotetext{
${ }^{8}$ This is a reasonable assumption to make in large metropolitan areas with very heterogeneous groups of consumers.
} 
Figure 1: Share of vendors producing $H$

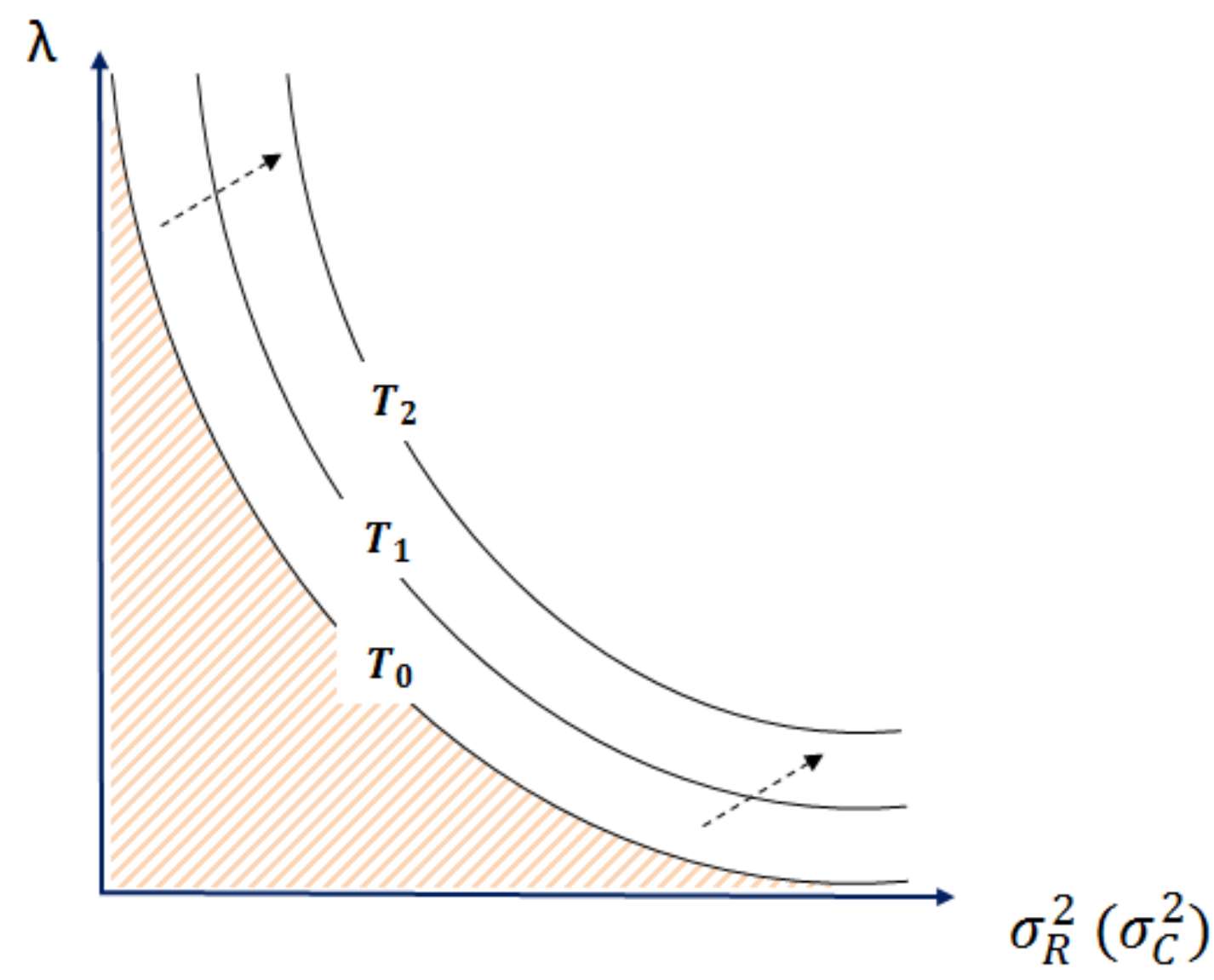

(on top of providing the training itself), leads to (i) An increase in the expected revenues $\mu_{R}$ and a decrease in the uncertainty $\sigma_{R}^{2}$ of these revenues (on top of a decrease in $\mu_{C}$ and $\sigma_{C}^{2}$ ) and (ii) A further increase in the share of vendors producing $H$.

According to Hypothesis 1 , the (ex ante) share of vendors producing $H$ is depicted under the curve T1 in Figure 1 and that according to Hypothesis 2 is depicted under the curve T2. Both hypotheses are brought to data in this paper. It is worth pointing out that our primary purpose is not going to separately estimate the parameters $\mu_{R}, \mu_{c}, \sigma_{R}^{2}, \sigma_{C}^{2}$, or $\lambda$, of our model. The primary aim is to test whether, and to what extent, simple interventions acting on what we labeled "soft" costs (like awareness of food quality and safety), or on advertising the quality to consumers, are sufficient to boost a change in the share of vendors producing $H$. Indeed it is very likely that such hypothesized interventions are going to affect these parameters altogether. However, the model is still useful to understand the main incentives at play and to formulate interventions that can be implemented and replicated elsewhere. 


\subsection{Design of the Experiment}

Our experiment consisted of three initial phases: identification, mobilization, and randomization of vendors. These were followed by the survey collection, workshops, monitoring, and evaluation. During the identification phase, we selected suitable areas for the training based on the presence of a significant cluster of street-food vendors. This process led to the selection of 10 areas distributed across the entire city (see Figure 2). These neighborhoods differ in terms of socio-economic background, including different types of consumers. For instance, some vendors are located in business districts, others are close to schools or public transportation.

Figure 2: Map of Kolkata

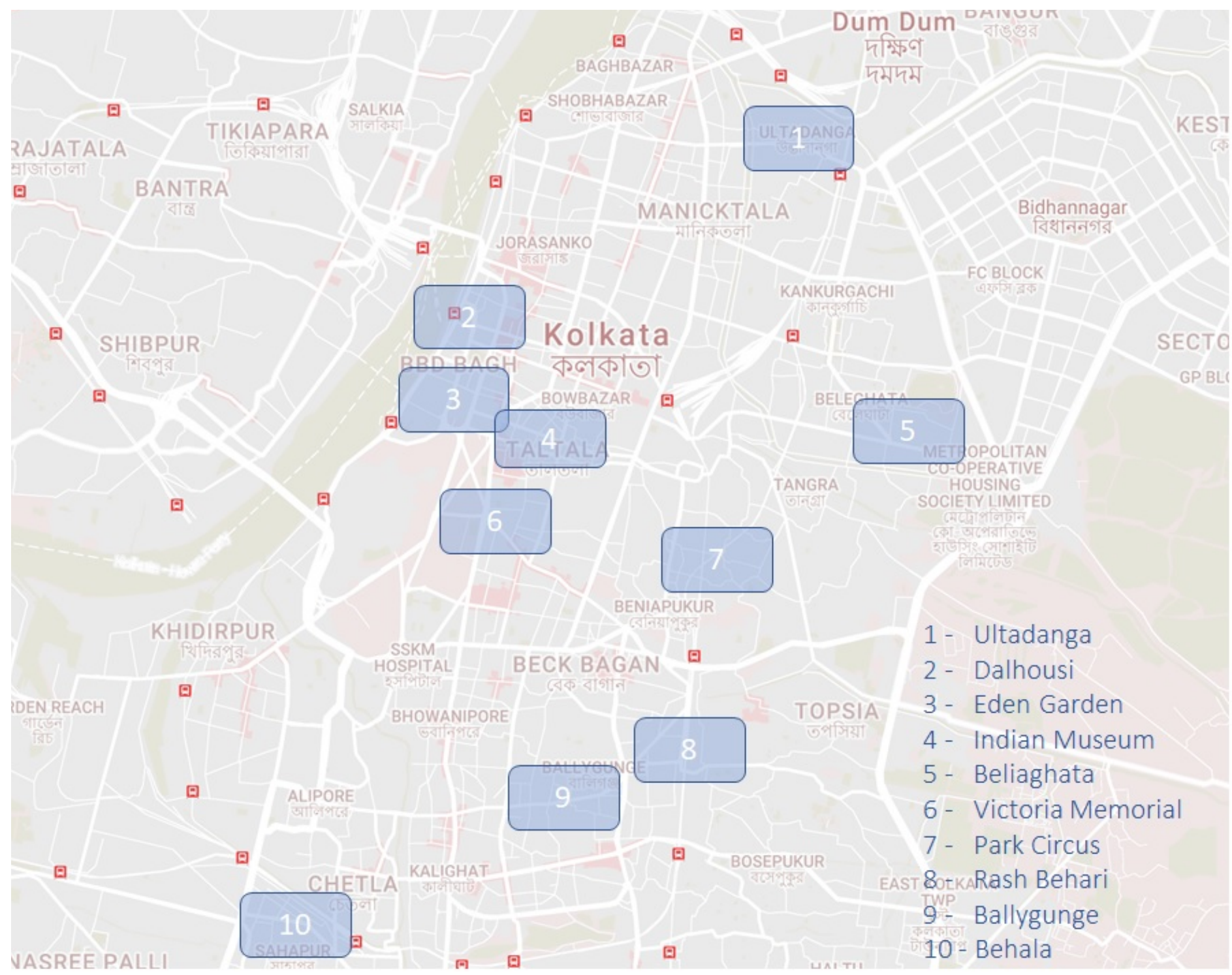

Notes: This figure shows a map of Kolkata with the 10 selected areas of our intervention. The 74 blocks of vendors that were selected for the analysis are spread out across these 10 areas. Each area is represented by both treated and non treated vendors.

The mobilization phase proceeded in the following way. Since street vending is an informal activity and vendors are generally organized in informal groups, we had to first engage "local vendors leaders", who are informal representatives of vendors on the street and often affiliated to vendors' unions. Our team made arrangements with several leaders throughout the city who represented 
a total of more than 2,000 vendors. Based on their location, we clustered them in 200 blocks of roughly 10 vendors each. ${ }^{9}$ From these blocks, we randomly selected 100 blocks that constituted our initial sample. 26 of them were used as pilot to evaluate the workshops, and the remaining 74 constituted our preferred sample for the analysis. ${ }^{10}$

This phase was also aimed at guaranteeing a satisfactory take-up rate. To ensure that, our team visited the selected areas to explain to the eligible vendors the benefits of attending a series of workshops focused on food safety. Table 1 provides summary statistics of the most important elements of our experimental design. Overall, we included 681 vendors in the study at the baseline, of which 230 vendors (25 blocks) were assigned to the control group (C), 210 vendors (23 blocks) were assigned to the first treatment group (T1), eligible to the training and the follow-up sessions, whereas 241 vendors (26 blocks) were assigned to the second treatment group (T2), eligible to receive promotional material endorsing their participation in the program, on top of the training and follow-ups. T1 and T2 are going to allow us to test Hypothesis 1 and 2, respectively, outlined in Section 2.2.

Within each area, we randomly allocated vendors to treatment and control groups, so as to ensure that all areas were represented among all three types of vendors. The treatment was assigned at the block level, that is, all vendors in the same block were made eligible to attend the workshops together. As one can see from Table 1, all 3 workshops were attended by at least $70 \%$ of the eligible vendors. ${ }^{11}$ Moreover, we were also successful at keeping high the take-up rate of the monitorings and also the endline survey. Notice that, one possible concern from the point of view of the identification, is that vendors working in blocks next to each other, but assigned to different treatments, may lead to confounding spillover effects in their behavior, which would be difficult to control. We address this issue by collecting precise information on each vendor's network on the street, as it will be explained in details in Section 3.

In order to be able to discern some of the incentives underlying the behavior of the vendors,

\footnotetext{
${ }^{9} \mathrm{~A}$ "block" is arbitrarily defined by us for convenience, on the basis of the presence of vendors and its natural location on the street. For example, a street (or portion of) between 2 large infrastructures that naturally divides vendors, may constitute a block. The definition of a block also facilitated the choice of the optimal time and location for the workshops, and fostered cooperation among vendors in the same block by providing them with a platform to come together. Our choice is sound and motivated also by the fact that vendors do not move across blocks, as they work in permanent built-up stalls.

${ }^{10}$ The selection of the number of blocks and vendors was decided on the basis of a conservative power analysis, assuming an effect size of 0.20 standard deviations. Whereas we assume an intra cluster correlation coefficient of 0.10 . Furthermore, the pilot group was evaluated between March 2015 and October 2015. This group was crucial to improve several aspects of the research design, as the length and accuracy of the survey, the reliability of the direct monitoring and the quality of the workshops. We control for the proximity to the pilot blocks, and use them in additional robustness checks.

${ }^{11}$ This includes the presence of other stall representatives at the workshops, if the owners themselves could not always attend. In our analysis we can always observe whether the owner of the stall attended all the workshops or not, and who else (like a family member) attended the workshop on his/her behalf. All results that will follow are robust to these controls.
} 
Table 1: Data Collection and Workshops

\begin{tabular}{|c|c|c|c|c|c|c|c|c|}
\hline & \multicolumn{2}{|c|}{$\begin{array}{c}\text { Training } \\
\text { (T1) }\end{array}$} & \multicolumn{2}{|c|}{$\begin{array}{c}\text { Training } \\
\text { w/Signal } \\
\text { (T2) }\end{array}$} & \multicolumn{2}{|c|}{$\begin{array}{l}\text { Control } \\
\text { (C) }\end{array}$} & \multicolumn{2}{|c|}{$\begin{array}{c}\text { Full } \\
\text { sample }\end{array}$} \\
\hline & $\mathrm{N}$ & take-up & $\mathrm{N}$ & take-up & $\mathrm{N}$ & take-up & $\mathrm{N}$ & take-up \\
\hline & \multicolumn{8}{|c|}{ Panel (A): Representation in the City of Kolkata } \\
\hline \# Areas & 10 & & 10 & & 10 & & 10 & \\
\hline \multirow[t]{2}{*}{ \# Blocks } & 23 & & 26 & & 25 & & 74 & \\
\hline & \multicolumn{8}{|c|}{ Panel (B): Number of observations: pre, during and post intervention } \\
\hline Baseline & 210 & 1.00 & 241 & 1.00 & 230 & 1.00 & 681 & 1.00 \\
\hline Monitoring \#1 & 171 & 0.81 & 183 & 0.76 & 189 & 0.82 & 543 & 0.80 \\
\hline Monitoring \#2 & 166 & 0.79 & 187 & 0.78 & 184 & 0.80 & 537 & 0.79 \\
\hline Monitoring \#3 & 171 & 0.81 & 216 & 0.90 & 201 & 0.87 & 588 & 0.86 \\
\hline Monitoring \#4 & 172 & 0.82 & 204 & 0.85 & 192 & 0.83 & 568 & 0.83 \\
\hline \multirow[t]{2}{*}{ Endline } & 176 & 0.84 & 192 & 0.80 & 193 & 0.84 & 561 & 0.82 \\
\hline & \multicolumn{8}{|c|}{ Panel (C): Attendance of the workshops } \\
\hline Workshop \#1 & 184 & 0.79 & 230 & 0.73 & & & 414 & 0.76 \\
\hline Workshop \#2 & 184 & 0.75 & 224 & 0.70 & & & 408 & 0.72 \\
\hline Workshop \#3 & 176 & 0.70 & 119 & 0.71 & & & 295 & 0.71 \\
\hline $\begin{array}{l}\text { Notes: The table pr } \\
\text { We included } 681 \text { ve } \\
\text { blocks) were assigne } \\
\text { group (T1), whereas } \\
\text { had a baseline and e } \\
\text { left (right) column o } \\
\text { in all cases. }\end{array}$ & vides & $\begin{array}{l}\text { mmary sta } \\
\text { the study } \\
\text { ontrol gro } \\
\text { dors ( } 26 \mathrm{bl} \\
\text { rveys, toge } \\
\text { nel shows }\end{array}$ & $\begin{array}{l}\text { cs of } t \\
\text { ne bas } \\
\text { C), } 21 \\
\text { wer } \\
\text { with } \\
\text { numbe }\end{array}$ & $\begin{array}{l}\text { most im } \\
\text { ine from } 1 \\
\text { vendors ( } 2 \\
\text { assigned to } \\
\text { monitoring } \\
\text { of observa }\end{array}$ & $\begin{array}{l}\text { ant ele } \\
\text { ifferen } \\
\text { locks) }\end{array}$ & $\begin{array}{l}\text { lents of or } \\
\text { areas, of } \\
\text { ere assign } \\
\text { treatmen } \\
\text { between o } \\
\text { ap rates). }\end{array}$ & $\begin{array}{l}\text { xperim } \\
\text { h } 230 \\
\text { the fi } \\
\text { up (T2 }\end{array}$ & $\begin{array}{l}\text { tal design } \\
\text { endors }(25 \\
\text { t treatmen } \\
\text { The study } \\
\text { havior. The } \\
\text { rate is higl }\end{array}$ \\
\hline
\end{tabular}

we differentiated between two treatment arms by providing additional promotional materials to a sub-sample of vendors. ${ }^{12}$ Specifically, they received posters, napkins and certificates, endorsing their participation in the program, thereby explicitly signaling to customers their attempt to cope with food-safety. Figure 3, Panel (A), shows a translated version (from Bengali) of the posters displayed by vendors at their kiosk, whereas Panel (B) shows a sample of the napkins provided by our partners on the right. We designed the treatment together with InnoAid marketing experts and our local partners. Our objective was to maximize the probability that the intervention for this group would not go unnoticed to the customers. Our concern is motivated by evidence showing that, although consumers declare to be concerned about food safety (WHO, 2008a; FAO, 2013), they might not necessarily recognize food safety hazards, and in turn, food safety improvements. Therefore, the purpose of the promotional material is to explicitly signal vendors' engagement with this problem.

\footnotetext{
${ }^{12}$ This treatment group attended the workshops only after the conclusion of the workshops for the first treatment group. We further deal with this point in Section 4.
} 
Figure 3: Posters and Napkins

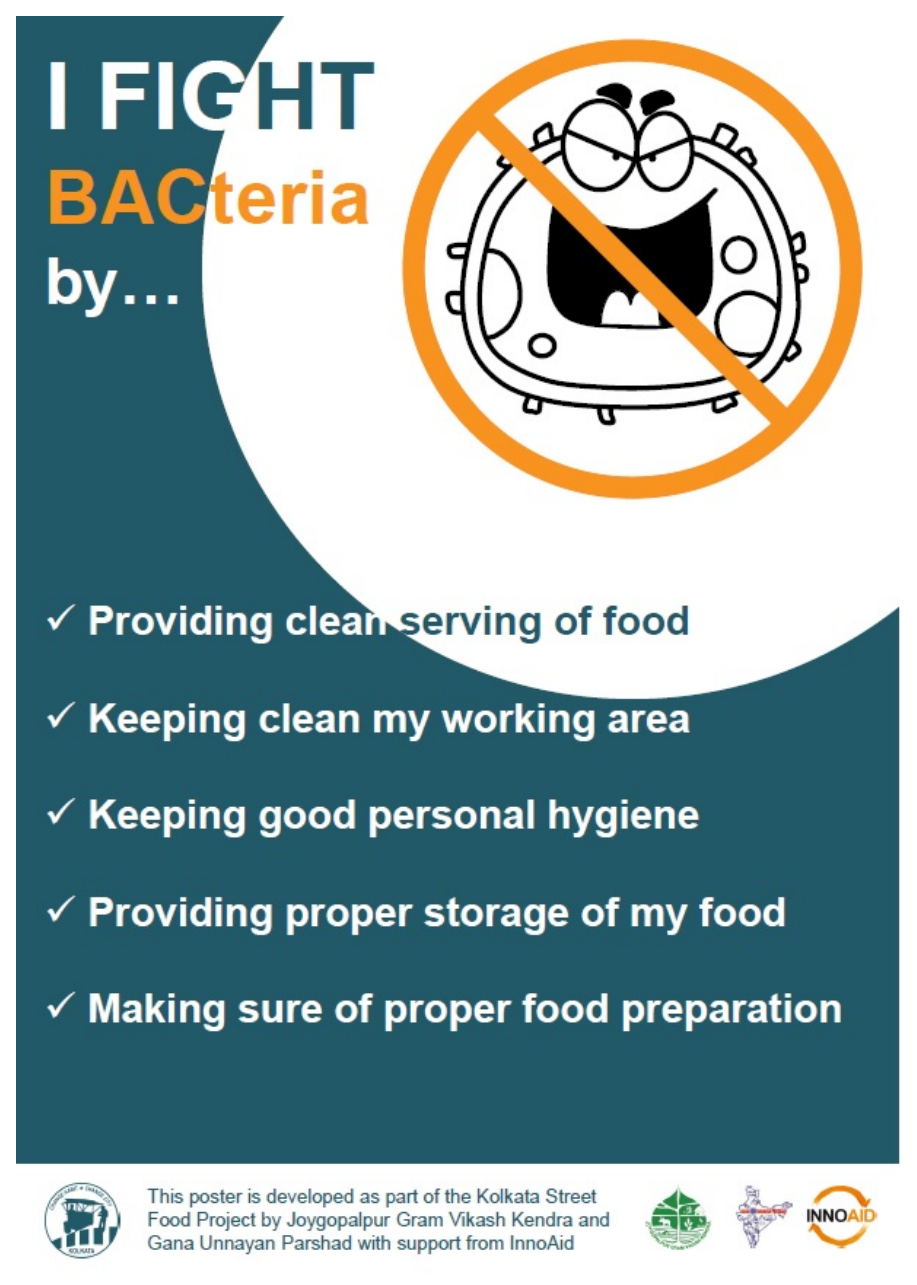

(A) Posters

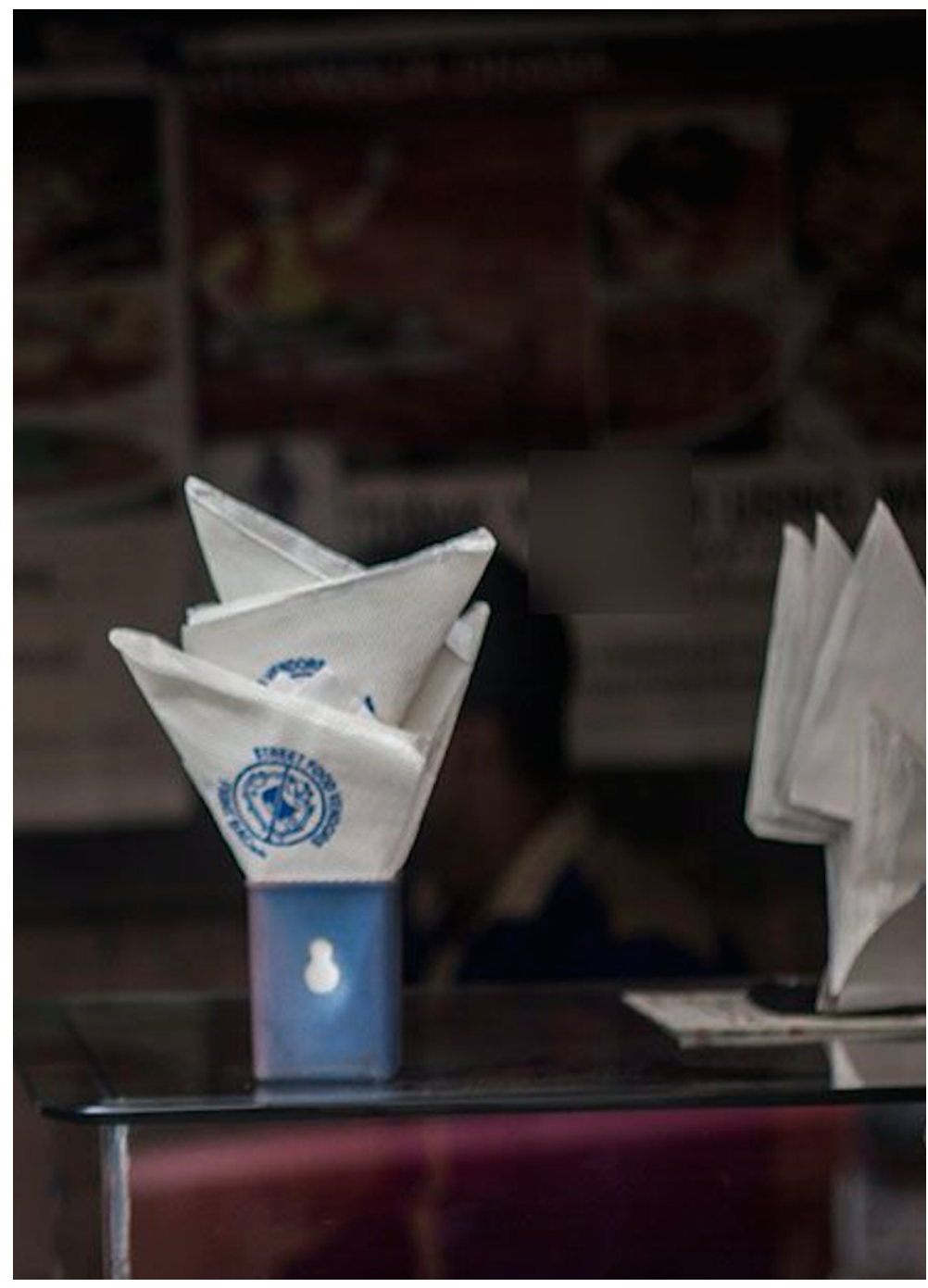

(B) Napkins

Notes: The figure shows the promotional materials provided to vendors in the second treatment arm (T2). Panel (A) shows a translated

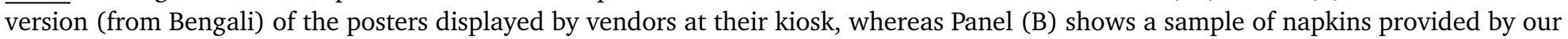
partners on the right. The promotional materials were designed by Innoaid marketing experts (and approved by Innoaid's local partners) as to reassure us that the intervention for this treatment group would not go unnoticed to the customers.

\subsection{Training and Workshops}

At the beginning of the program, we administered a baseline survey to all vendors, in order to obtain socio-economic and demographic information, as well as to have a clear picture of their business practices and food safety awareness before the intervention. Consistent with the literature outlined in Section 2.1, in our baseline survey we also find that only a minority of vendors are able to mention possible causes of food contamination. Table 2 reports summary statistics from a set of variables preliminarily investigating vendors' food-safety knowledge. ${ }^{13}$ First, we ask whether they know about the ongoing debate on the National Act to formalize street-vending. Only $11 \%$ of them reply to be aware of it. Second, we ask vendors to list any possible source of food contamination: only a minority of them are able to do it. The most mentioned one is bacteria (22\%), while only

\footnotetext{
${ }^{13}$ These questions are included only in the baseline survey, at the beginning of the project, with the purpose of providing suggestive evidence on the lack of food-safety awareness within our sample. Conversely, in the endline survey, we collect a different and more comprehensive set of questions covering all different aspect of food safety knowledge (see Section 3).
} 
$10 \%$ of vendors mention water contamination. This preliminary evidence also suggests that the level of food-safety awareness is similarly limited across groups, as there are no significant differences across groups.

Table 2: Pre-Intervention: Food safety knowledge and balancing

\begin{tabular}{lccccccc}
\hline & $\begin{array}{c}\text { Training } \\
\text { (T1) }\end{array}$ & $\begin{array}{c}\text { Training } \\
\text { w/Signal } \\
\text { (T2) }\end{array}$ & $\begin{array}{c}\text { Control } \\
\text { (C) }\end{array}$ & $\begin{array}{c}\text { Full } \\
\text { sample }\end{array}$ & \multicolumn{2}{c}{ P-value difference } \\
& 0.11 & 0.11 & 0.10 & 0.11 & 0.54 & 0.60 & 0.94 \\
National act & & & & & & & \\
Contamination is caused by: & & 0.19 & 0.20 & 0.22 & 0.38 & 0.89 & 0.27 \\
Bacteria & 0.27 & 0.192 & T2 = C & T1 = T2 \\
Kerosene, detergent, etc & 0.01 & 0.02 & 0.02 & 0.02 & 0.81 & 0.80 & 0.57 \\
Food colouring & 0.08 & 0.13 & 0.09 & 0.10 & 0.61 & 0.27 & 0.11 \\
Insects & 0.18 & 0.20 & 0.13 & 0.17 & 0.30 & 0.17 & 0.67 \\
Dirt & 0.23 & 0.23 & 0.20 & 0.22 & 0.70 & 0.70 & 0.99 \\
Contaminated water & 0.08 & 0.13 & 0.10 & 0.10 & 0.44 & 0.56 & 0.11 \\
\hline Observations & 210 & 241 & 230 & 681 & & &
\end{tabular}

Notes: The table reports summary statistics from a set of variables preliminarily investigating vendors' food-safety knowledge in each of the treatment arm. Each column for T1, T2, C and Total reports the mean value. P-values are based on standard errors clustered by block.

The vendors assigned to treatment were then eligible to attend three workshops of about 1.5 hours each and a series of three follow-ups at the vendor's kiosk. The workshops took place between October 2015 and May 2016 in areas close to the vendors' working place. ${ }^{14}$ This was decided in order to facilitate the identification of attending' vendors and to assure an homogeneous environment across vendors' workshops.

Each meeting took place approximately every $2-3$ weeks and it focused on specific topics. Workshop 1 focused on providing information on the Street Vendors Act 2014, aiming at increasing vendors' awareness of their rights and of the ongoing formalization process. This workshop also focused on the importance of cooperation among vendors to achieve common goals. Workshop 2 included a wide range of information about food-safety hazards related to the vendors' daily behaviors. Workshop 3 focused on how to change daily behavior to reduce food-safety hazards. For instance, it stressed the importance of hands cleaning, vendors' personal hygiene, use of containers for water, food covering, availability of paper plates and cups, and waste management. The followups consisted of 1-to-1 meetings at the vendor's kiosk, where a trainer could observe the vendor and suggest personalized advices to improve his food-safety practices. More information on each workshop are provided in the Online Appendix.

The workshop phase was accompanied by 4 rounds of monitoring, where data collectors ob-

\footnotetext{
${ }^{14}$ The locations (e.g. unions offices, building premises) varied depending on the local availability of indoor areas close to the vendors working place.
} 
served and recorded the food safety practices adopted by the vendors (this means that, together with the baseline and endline surveys, we collected a total of 6 data points on behavior). This information was collected by actually observing the vendors at their stalls, instead of asking them questions, so as to minimize reporting errors. Several precautions were taken to ensure that the monitoring captured the vendors' actual food handling practices, and that the vendors were not altering their behavior for the survey: i) The data collectors for the monitoring rounds were not involved with the actual training, so that they were unknown to the vendors; ii) The vendors had no prior knowledge of when their stall would be monitored (while they were obviously aware of being monitored at some point); iii) The monitoring was undertaken by 2 teams of 2 data collectors visiting each block together; they were approaching from either side of the street, so that it would be difficult for vendors to be alerted and to behave differently on seeing the interviewers on either side of the street; iv) For additional accuracy, the data collectors also took pictures of the stalls, which were then cross-checked with the data.

Finally, at the end of the program, we collected an endline survey that repeated the monitoring of the vendors' food handling practices and also collected general information on their business practices. The endline also included detailed questions targeted at understanding whether the vendors had learnt about safer food handling methods or engaged in any of the practices advocated by the training workshops.

\section{Data}

\subsection{Independent Variables and Balancing}

One of the novelties of our study is the degree of accuracy of the data collected about street-vendors' information and practices. Table 3 provides socio-economic and demographic information of the vendors in each of the treatment arm. The last column of the table reports the p-value for the means of the two treatment groups and the control group being equal. As one can see, treatment and control blocks are statistically similar in terms of most baseline characteristics. In Panel (A) we can see that around $86 \%$ of vendors in our sample are male, which is not surprising given the heavily skewed gender ratio in this sector. Vendors' average age is about 41 years old and they have a remarkably long experience in this sector (19 years). Moreover, $72 \%$ of them have some 
education and approximately $70 \%$ of the vendors are associated with a union.

Table 3: Pre-Intervention: Summary statistics and balancing

\begin{tabular}{|c|c|c|c|c|c|c|c|}
\hline & Training & Training & Control & Full & \multicolumn{3}{|c|}{ P-value difference } \\
\hline & (T1) & $(\mathrm{T} 2)$ & (C) & & $\mathrm{T} 1=\mathrm{C}$ & $\mathrm{T} 2=\mathrm{C}$ & $\mathrm{T} 1=\mathrm{T} 2$ \\
\hline & \multicolumn{7}{|c|}{ Panel (A): Socioeconomic and demographic information } \\
\hline Male & 0.85 & 0.87 & 0.87 & 0.86 & 0.72 & 0.96 & 0.77 \\
\hline Age & 40.32 & 41.41 & 41.01 & 40.94 & 0.60 & 0.75 & 0.45 \\
\hline Years of vending & 19.21 & 19.20 & 19.97 & 19.47 & 0.60 & 0.64 & 0.99 \\
\hline Some education & 0.73 & 0.72 & 0.71 & 0.72 & 0.37 & 0.63 & 0.68 \\
\hline \multirow[t]{2}{*}{ Member of a Union } & 0.70 & 0.66 & 0.74 & 0.70 & 0.63 & 0.38 & 0.70 \\
\hline & \multicolumn{7}{|c|}{ Panel (B): Business information } \\
\hline Cooked food & 0.71 & 0.68 & 0.77 & 0.72 & 0.23 & 0.14 & 0.71 \\
\hline Light food & 0.59 & 0.51 & 0.57 & 0.55 & 0.74 & 0.45 & 0.33 \\
\hline Heavy food & 0.13 & 0.12 & 0.15 & 0.14 & 0.59 & 0.51 & 0.92 \\
\hline Meals & 0.19 & 0.23 & 0.19 & 0.20 & 0.94 & 0.49 & 0.49 \\
\hline Drinks & 0.11 & 0.07 & 0.12 & 0.10 & 0.72 & 0.17 & 0.25 \\
\hline Fruits and vegetables & 0.06 & 0.09 & 0.05 & 0.07 & 0.62 & 0.37 & 0.58 \\
\hline Sweets & 0.05 & 0.08 & 0.06 & 0.06 & 0.75 & 0.57 & 0.39 \\
\hline Other & 0.01 & 0.01 & 0.04 & 0.02 & 0.35 & 0.24 & 0.54 \\
\hline Revenue & 1294 & 1463 & 1253 & 1337 & 0.81 & 0.45 & 0.53 \\
\hline Expenditure & 954 & 1125 & 928 & 1003 & 0.84 & 0.42 & 0.47 \\
\hline Profits & 339 & 338 & 326 & 334 & 0.76 & 0.77 & 0.97 \\
\hline \multirow[t]{2}{*}{ Hours worked } & 11 & 11 & 11 & 11 & 0.98 & 0.73 & 0.77 \\
\hline & \multicolumn{7}{|c|}{ Panel (C): Daily problems faced } \\
\hline Bribes to police & 0.37 & 0.30 & 0.37 & 0.35 & 0.79 & 0.41 & 0.27 \\
\hline Daily problems faced are: & & & & & & & \\
\hline Lack of electricity connection & 0.44 & 0.49 & 0.51 & 0.48 & 0.35 & 0.67 & 0.54 \\
\hline Shortage of capital & 0.34 & 0.32 & 0.34 & 0.33 & 0.94 & 0.76 & 0.79 \\
\hline Competition from vendors & 0.20 & 0.19 & 0.12 & 0.17 & 0.18 & 0.26 & 0.90 \\
\hline Competition from other & 0.06 & 0.03 & 0.03 & 0.04 & 0.24 & 0.89 & 0.37 \\
\hline Lack of toilets & 0.48 & 0.61 & 0.55 & 0.55 & 0.48 & 0.43 & 0.16 \\
\hline Lack of drinkable water & 0.45 & 0.58 & 0.52 & 0.52 & 0.44 & 0.45 & 0.14 \\
\hline \multirow[t]{2}{*}{ Extortion and bribes from police } & 0.18 & 0.11 & 0.16 & 0.15 & 0.79 & 0.41 & 0.27 \\
\hline & \multicolumn{7}{|c|}{ Panel (D): Network (number of vendors known) } \\
\hline Own block & 7.56 & 7.77 & 7.76 & 7.70 & 0.68 & 0.99 & 0.66 \\
\hline \multirow[t]{2}{*}{ Neighboring blocks } & 4.65 & 4.64 & 4.84 & 4.71 & 0.79 & 0.77 & 0.99 \\
\hline & \multicolumn{7}{|c|}{ Panel (E): Observed behavior } \\
\hline Facilities index & 0.48 & 0.44 & 0.46 & 0.46 & 0.77 & 0.19 & 0.12 \\
\hline Food handling index & 0.64 & 0.60 & 0.61 & 0.62 & 0.44 & 0.67 & 0.21 \\
\hline Costumers index & 0.69 & 0.68 & 0.69 & 0.69 & 0.92 & 0.89 & 0.76 \\
\hline Total index & 0.60 & 0.56 & 0.57 & 0.58 & 0.55 & 0.33 & 0.11 \\
\hline Observations & 210 & 241 & 230 & 681 & & & \\
\hline
\end{tabular}

Notes: The table provides socio-economic and demographic information (Panel A), business information (Panel B), daily problems faced by vendors (Panel C), network information (Panel D) and observed behavioral outcomes (Panel E) in each of the treatment arm. Each column for T1, T2, C and Total reports the mean value. P-values are based on standard errors clustered by block.

In Panel (B) we can see that roughly $72 \%$ of vendors in our sample sell cooked food at the stall. The second most represented category are vendors selling light food (55\%), followed by vendors selling meals (20\%), heavy food (14\%), drinks (10\%), fruits and vegetables (7\%) and 
sweets (6\%). Vendors profit on average 334 Rupees a day, which is well above the poverty threshold line (35 Rupees in 2015). Whereas Panel (C) shows that vendors are concerned with a wide set of problems, such as lack of basic infrastructures (electricity, clean water and toilets), extortion and capital constraints. In Section 4.2, we discuss to what extent this set of obstacles might affect vendors' behaviors.

We also collected data on the network for each vendor. Specifically, we showed each of them a picture of the other vendors on the block, as well as the vendors in the two neighboring blocks, and asked: (i) Whether they know this vendor well; (ii) Whether this is a family member; (iii) How often they interact with him during the week. This gives us crucial information on the possible flow of information. As we can see in Table 3, Panel (D), on average, vendors from all the treatment arms know a similar number of people from their own blocks (7.7 vendors), as well as their neighboring blocks (4.7 vendors). Finally, Panel (E) provides information about the balance for the variables on observed behavior. These outcomes are explained and discussed in the next subsection.

\subsection{Outcome Variables}

We now turn to the first inspection of our outputs of interest as measured at the endline, after the intervention. This gives us a first overview of the effects which are then measured with precision in Section 4. The variables are divided into 3 groups: (i) Awareness, capturing to what extent vendors are aware of food safety matters; (ii) Claimed behavior, capturing vendors' self-reported actions taken to improve their behavior with respect to food safety; and (iii) Observed behavior, capturing vendors' behavior as observed by the data collectors. While the data on the latter were collected by observing vendors in all 6 survey rounds, data on the first 2 variables were collected only at the endline. In what follows, we discuss each category of outcome variables in detail.

First, regarding Awareness, the endline survey asked vendors what according to them constitutes personal hygiene and food hygiene, what some common contaminants of food are, and the reasons for using clean utensils. ${ }^{15}$ Based on these, we compute a proxy of awareness which takes value 1 if the vendor mentioned any point at all and 0 otherwise. ${ }^{16}$ It is worth noting that these outcome

\footnotetext{
${ }^{15}$ The list of answers was (a) food hygiene: covering food, separating cooked and raw food, storing food at the proper temperature, handle food with proper implements, washing ingredients before cooking, using clean water, and using clean utensils; (b) personal hygiene: having clean hands, using soap, wearing clean clothes, having clean and short nails, wearing aprons, wearing caps, wearing gloves, taking regular baths, and using clean water; and (c) possible contaminants: bacteria in food, kerosene oil or detergent, food coloring, insects, dirt and contaminated water.

${ }^{16}$ In the robustness checks we also calculate an alternative proxy for awareness: we count the number of relevant points the vendor mentioned, and normalize this number. The qualitative results of our analysis do not change.
} 
variables are based on whether the vendor can clearly enumerate relevant hygienic practices. Vendors who know the answers, but do not say it, are observationally equivalent to those who are not aware. Thus, part of what we are identifying is whether the training makes different aspects of hygienic practices more salient, easier to think about systematically, articulate, and enumerate, for the vendors. Panel (A) of Table 4 reports the proportion of vendors who can provide any answer, for each of the three treatment arms. We see that this proportion is consistently higher for the two treatment arms compared to the control.

Table 4: Post-Intervention: Summary of main output variables

\begin{tabular}{|c|c|c|c|c|}
\hline & $\begin{array}{c}\text { Training } \\
\text { (T1) }\end{array}$ & $\begin{array}{l}\text { Training } \\
\text { w/Signal } \\
\text { (T2) }\end{array}$ & $\begin{array}{l}\text { Control } \\
\text { (C) }\end{array}$ & $\begin{array}{c}\text { Full } \\
\text { sample }\end{array}$ \\
\hline & \multicolumn{4}{|c|}{ Panel (A): Food safety awareness } \\
\hline Food hygiene & 0.70 & 0.67 & 0.58 & 0.65 \\
\hline Personal hygiene & 0.80 & 0.77 & 0.75 & 0.77 \\
\hline Contamination & 0.73 & 0.72 & 0.69 & 0.71 \\
\hline \multirow[t]{2}{*}{ Utensiles } & 0.84 & 0.86 & 0.77 & 0.82 \\
\hline & \multicolumn{4}{|c|}{ Panel (B): Claimed Behavior } \\
\hline Discussions & 0.24 & 0.21 & 0.05 & 0.17 \\
\hline Get information & 0.16 & 0.16 & 0.07 & 0.13 \\
\hline Improvements & 0.47 & 0.43 & 0.27 & 0.39 \\
\hline Investments & 0.09 & 0.05 & 0.06 & 0.07 \\
\hline Discuss NA & 0.12 & 0.12 & 0.03 & 0.09 \\
\hline Information on NA & 0.11 & 0.08 & 0.06 & 0.08 \\
\hline Unionns & 0.04 & 0.05 & 0.04 & 0.04 \\
\hline \multirow[t]{2}{*}{ Meetings } & 0.10 & 0.12 & 0.04 & 0.09 \\
\hline & \multicolumn{4}{|c|}{ Panel (C): Observed Behavior } \\
\hline Facilities index & 0.54 & 0.50 & 0.51 & 0.52 \\
\hline Food handling index & 0.80 & 0.80 & 0.83 & 0.81 \\
\hline Costumers index & 0.64 & 0.60 & 0.62 & 0.62 \\
\hline Total index & 0.64 & 0.60 & 0.64 & 0.63 \\
\hline Observations & 176 & 192 & 193 & 561 \\
\hline
\end{tabular}

Notes: The table provides a first inspection of our outputs of interest as measured at the endline, after the intervention. This gives us a first overview of the effects which are then measured with precision in Section 4. The variables are divided into 3 groups: Panel (A) reports measures of Awareness, capturing to what extent vendors are aware of food safety matters; Panel (B) reports measures of Claimed behavior, capturing vendors' self-reported actions taken to improve their behavior with respect to food safety; and Panel (C) reports Observed behavior, capturing vendors' behavior as observed by the data collectors.

Second, regarding Claimed behavior, the endline questionnaire included a set of questions directly inquiring whether the vendor had engaged in any of the following activities over the last six months: (i) Discussing food safety with other vendors; (ii) Trying to obtain more information on food safety; (iii) Trying to improve the hygiene and sanitation levels at their stalls; (iv) Buying 
new utensils or investing in community solutions such as a bigger waste bin for multiple vendors on that street; (v) Talking about the National Act with other vendors; (vi) Trying to find out more information about the National Act; (vii) Discussing it with their unions; and (viii) Interacting with other vendors about food safety improvements. Vendors could either agree or disagree that they had engaged in either of these actions. Based on their answers, we define a dummy variable, corresponding to each action, taking the value 1 if the vendor had participated in that activity and 0 otherwise. The proportion of vendors engaging in each of these activities is reported in Panel (B) of Table 4. Again, we see that this proportion is, on average, much higher for the treated vendors compared to the control group. For instance, as many as $24 \%$ of the vendors in the first treatment group and $21 \%$ of vendors in the second treatment group report that they have engaged in discussions with other vendors about safe food handling, while this proportion is only $5 \%$ for the control vendors.

Third, regarding Observed behavior, the variables are defined on the basis of the information collected on observed vendors' food safety practices, and can be grouped into 4 broad categories. ${ }^{17}$ The first category is Facilities, and it is applicable to all vendors. We assigned vendors scores based on: (i) Whether they used an apron and a proper dustbin; (ii) Whether there was safe drinking water; (iii) Whether the vendor was using a clean cloth to wipe his hands; and (iv) Whether there was food debris or waste on the floor of the stall or in the cooking area. We then calculated the percentage of the total score that the vendor received and obtained the final "Facilities index". For instance, a vendor exhibiting perfect behavior on all dimensions would get a score of $100 \%$ on this index. The index for the second category, Handling, is similarly constructed and based on scores assigned for: (i) Whether the ingredients are covered and separated from the cooked food; (ii) Whether the cooked food is covered; and (iii) Whether tongs, spatulas or other implements are used to cook and to serve (as opposed to touching the food with bare hands). This index is relevant only for vendors who are actually cooking food at the stall, and not for vendors who only sell precooked or pre-packaged snacks, cut fruits, beverages etc. The corresponding index for the third category, Customer, is calculated based on scores for: (i) Whether there are food debris on the tables, chairs or benches; (ii) Whether the vendor uses disposable plates, cups and cutlery; and (iii)

\footnotetext{
${ }^{17}$ Since these data on behavior are obtained only by observation and not by interacting with the vendors, these variables are missing in the data both when a question is not relevant for a particular vendor as well as when the data collector cannot determine what the vendor's usual behavior is in some particular aspect (e.g. if they happened to visit the stall when there were no customers, they might not be able to ascertain whether the vendors were serving the food on disposable plates). Since our purpose is to have an overall idea about whether the vendors improve their food handling methods, and we should ideally use all of our sample to have enough statistical power, we aggregate the outcome variables for each category so as to maximize the number of observations.
} 
Whether the non-disposable utensils (usually made of steel) are washed with soap. This last index is applicable only for those vendors who have accommodations for customers to actually sit and eat at the stall. Finally, the index Total is the sum of the 3 period indices and it is representative of the general (audited) observed vendors' behavior or hygiene practices of the street-food vending sector in Kolkata. The Online Appendix includes further details on how each of these indices was constructed.

As shown in Panel (C) of Table 4, vendors displayed an average score of 52\% for the facilities index, around $81 \%$ for the food handling index, around $62 \%$ for the customer service index, and $63 \%$ for the total index. Differently from the other two set of output variables, there seems to be no marked difference between the groups in terms of these observed indices at the time of the endline. ${ }^{18}$ This result is going to be further investigated in the next sections.

\section{Empirical Strategy and Results}

\subsection{Specifications}

We now aim to measure the effects of the intervention more precisely. Our identification strategy exploits the random assignment of blocks of vendors to the different treatment groups, to recover the effect of being assigned to the training on each of 3 categories of outcome variables. We use both a difference and a difference-in-difference approach, depending on the outcome considered. In what follows, we discuss each specification in detail.

Our baseline specification is:

$$
y_{i t}=\alpha+\beta T_{i}+\mathbf{X}_{i} \gamma+\delta_{t}+\varepsilon_{i t}
$$

where $y_{i t}$ is the outcome variable for vendor $i$ in period $t, T_{i}$ is a dummy variable indicating the treatment status of vendor $i, X_{i t}$ is a vector of several controls such as the vendors' age, gender and years of experience, the area of the city where the stall is located, whether the stall sells cooked food, the number of pilot blocks within a $1 \mathrm{~km}$ radius, and $\delta_{t}$ is a period fixed effect. In this specification, as well as in those that follows, standard errors are robust and clustered at the block level. The randomization of treatment implies that the coefficient $\beta$ yields an unbiased effect of the

\footnotetext{
${ }^{18}$ Notice that these indices are balanced between groups at the time of the baseline survey. Results are reported in Panel (E) of Table 3.
} 
intervention. It is worth noting here that we consider the Intention-To-Treat (ITT) estimate as the policy relevant parameter for our purpose, since the broad question that we are interested in is to identify the effect of this intervention were it to be replicated exactly on a larger scale. ${ }^{19}$

In order to separately identify the effects of the two different treatments, and to compare their effects, we estimate an identical specification with a dummy for each treatment, as follows:

$$
y_{i t}=\alpha+\beta_{1} T_{1, i}+\beta_{2} T_{2, i}+\mathbf{X}_{i} \gamma+\delta_{t}+\varepsilon_{i t}
$$

where $T_{1, i}$ refers to the treatment group with only the training, whereas $T_{2, i}$ refers to the treatment group with both training and signal.

To examine whether the effects of the workshops persist over time, we use the workshop timing information, and create time lag variables that denote the number of months that have elapsed since the last workshop the vendor was scheduled to attend. ${ }^{20}$ We interact these time dummies with treatment assignment, and estimate a specification of the form:

$$
y_{i t}=\alpha+\sum_{m=1}^{5} \beta_{m} T^{*} \operatorname{lag}_{m, i t}+\mathbf{X}_{i} \gamma+\delta_{t}+\varepsilon_{i t}
$$

where $l a g_{m, i t}$ is a dummy for whether the number of months that have elapsed since the last workshop equals $m$, and $T^{*} \operatorname{lag}_{m, i t}$ denotes the treatment dummy interacted with the $l a g_{m, i t}$ dummy variable. $\beta_{m}$ therefore allows us to discern whether the treatment vendors were exhibiting outcomes significantly different from the control vendors if they were $m$ months into the training.

Because the treatment is randomized, a simple comparison of treatment and control group vendors does not suffer from endogeneity due to differences in pre-treatment trends. The staggered nature of the training and the multiple rounds of monitoring, however, enables us to determine how the vendors' behavior changes over time, as well as to estimate the effect of the training more precisely. We estimate a difference-in-difference specification, exploiting the difference in timing of the training administered to different blocks, as follows:

$$
y_{i t}=\alpha+\beta_{1} T^{*} \text { After }_{i t}+\beta_{2} T_{i}+\mathbf{X}_{i} \gamma+\delta_{t}+\varepsilon_{i t}
$$

\footnotetext{
${ }^{19}$ On the other hand, if we were interested in estimating whether the information provided changes the behavior of the vendors, a more appropriate parameter to recover would be LATE.

${ }^{20}$ Note that we are only using workshop scheduling information here, so that the time lag variables are defined in an identical manner for vendors who actually attended the workshops and those who did not. The last workshop date is the date a vendor was scheduled to attend workshop 3. In case this date was missing, we used the date the vendor was slotted to attend workshop 2.
} 
where After $_{i t}$ is a dummy variable for whether the data was collected after vendor $i$ had attended at least one workshop. Our coefficient of interest here is $\beta_{1}$, which measures the difference in pre and post training outcomes for the treatment groups, compared to the difference for the control group, and gives a more precise estimate of the training effect. ${ }^{21}$ We also examine whether the effect of the training varies across time in this difference-in-difference context, by splitting the After ${ }_{i t}$ dummy into a set of binary variables denoting different time lags since the workshop, similar to specification (5).

\subsection{Main Results}

In this section we report the results we obtained for each outcome variable. First, Table 5 reports the coefficients for the effects of the training program on vendors' Awareness. Panel (A) outlines the effects of belonging to any treatment group, i.e. $\beta$ in equation (3). As one can see, during the endline survey, vendors assigned to the training were on average more likely to recall a relevant issue about food hygiene $(8.2 \%$, or $8.2 / 58=14.1 \%$ of mean control group), personal hygiene $(2.6 \%)$, contamination of food (8\%), and cleanliness of utensils (9.7\%), as compared to the control group. Panel (B) shows the effects of the two treatment groups separately, i.e. $\beta_{1}$ and $\beta_{2}$ from equation (4). Notice that, even though the vendors in T2 were provided with the means of signaling to customers their participation in the training program, we do not see a larger improvement as compared to T1. Finally, Panel (C) further distinguishes between treated vendors in terms of their workshop attendance timing, reporting the results from estimating specification (5). The rows document, for each outcome, the difference in that outcome exhibited by treated group compared to the control, for vendors whose last workshop attendance was $2,3,4$, or 5 , months before the endline survey. We find evidence of persistence in the effect of the training for the outcomes pertaining to the cleanliness of utensils. Whereas in terms of food hygiene and contamination, the treated vendors whose last workshop was within the last 3 months exhibit better outcomes than the control, but not those who attended their last workshop more than 4 months back. ${ }^{22}$

Second, Table 6 reports identical coefficients for Claimed behavior, or actions that vendors claim

\footnotetext{
${ }^{21}$ Since the random assignment implies that the pre-training trends in outcome should be identical for treatment and control groups, the diff-in-diff estimate essentially measures the difference in treatment and control after the training. The $\beta$ coefficient in Equation (3) would then be $\beta_{1}$ in Equation (6) weighted by the probability of being observed after the workshop.

${ }^{22}$ Overall, we are unable to reject the hypothesis that the treated vendors corresponding to all 4 time lags are statistically indistinguishable in their behavior with outcomes. This suggests that, while awareness shows a marked improvement immediately following the workshops, the effect does not entirely dissipate over time.
} 
Table 5: Awareness about food safety: Difference specification

\begin{tabular}{|c|c|c|c|c|}
\hline & $\begin{array}{c}(1) \\
\text { Food } \\
\text { Hygiene }\end{array}$ & $\begin{array}{l}\text { (2) } \\
\text { Personal } \\
\text { Hygiene }\end{array}$ & $\begin{array}{c}(3) \\
\text { Contamination }\end{array}$ & $\begin{array}{c}\text { (4) } \\
\text { Utensils }\end{array}$ \\
\hline & \multicolumn{4}{|c|}{ Panel (A): Unique Treatment } \\
\hline Training (T1 or $\mathrm{T} 2$ ) & $\begin{array}{c}0.082^{* * * *} \\
(0.030)\end{array}$ & $\begin{array}{l}0.026 * \\
(0.013)\end{array}$ & $\begin{array}{l}0.080 * * \\
(0.040)\end{array}$ & $\begin{array}{c}0.097 * * * \\
(0.035)\end{array}$ \\
\hline $\begin{array}{l}\text { Observations } \\
\text { R-squared } \\
\text { Mean Dep. Var. (C) }\end{array}$ & $\begin{array}{c}561 \\
0.571 \\
0.580\end{array}$ & $\begin{array}{c}561 \\
0.782 \\
0.746\end{array}$ & $\begin{array}{c}561 \\
0.405 \\
0.694\end{array}$ & $\begin{array}{c}561 \\
0.299 \\
0.767\end{array}$ \\
\hline Mean Dep. Var. (C) & \multicolumn{4}{|c|}{ Panel (B): Separate Treatments } \\
\hline Training (T1) & $\begin{array}{l}0.075 \% * \\
(0.033)\end{array}$ & $\begin{array}{c}0.025 \\
(0.018)\end{array}$ & $\begin{array}{l}0.072 * \\
(0.043)\end{array}$ & $\begin{array}{l}0.094 * * \\
(0.039)\end{array}$ \\
\hline Training w/Signal (T2) & $\begin{array}{l}0.088^{* *} \\
(0.035)\end{array}$ & $\begin{array}{c}0.027 \\
(0.018)\end{array}$ & $\begin{array}{l}0.085^{*} \\
(0.045)\end{array}$ & $\begin{array}{l}0.099 * * \\
(0.039)\end{array}$ \\
\hline $\mathrm{p}$-value $(\mathrm{T} 1=\mathrm{T} 2)$ & 0.70 & 0.95 & 0.73 & 0.90 \\
\hline $\begin{array}{l}\text { Observations } \\
\text { R-squared } \\
\text { Mean Dep. Var. (C) }\end{array}$ & $\begin{array}{c}561 \\
0.571 \\
0.580\end{array}$ & $\begin{array}{c}561 \\
0.782 \\
0.746\end{array}$ & $\begin{array}{c}561 \\
0.406 \\
0.694\end{array}$ & $\begin{array}{c}561 \\
0.299 \\
0.767\end{array}$ \\
\hline Mean Dep. Var. (C) & \multicolumn{4}{|c|}{ Panel (C): Time-differentiated treatment } \\
\hline Training (T1 or T2) $\times$ 2-months & $\begin{array}{c}0.044 \\
(0.056)\end{array}$ & $\begin{array}{l}-0.001 \\
(0.055)\end{array}$ & $\begin{array}{c}0.091 \\
(0.070)\end{array}$ & $\begin{array}{c}0.071 \\
(0.063)\end{array}$ \\
\hline Training $(\mathrm{T} 1$ or $\mathrm{T} 2) \times 3$-months & $\begin{array}{c}0.089 * * * * \\
(0.033)\end{array}$ & $\begin{array}{c}0.025 \\
(0.016)\end{array}$ & $\begin{array}{l}0.099 * * \\
(0.047)\end{array}$ & $\begin{array}{l}0.097 * * \\
(0.045)\end{array}$ \\
\hline Training (T1 or T2) $\times$ 4-months & $\begin{array}{c}0.076 \\
(0.048)\end{array}$ & $\begin{array}{c}0.051 \\
(0.032)\end{array}$ & $\begin{array}{c}0.058 \\
(0.059)\end{array}$ & $\begin{array}{c}0.155 * * * \\
(0.044)\end{array}$ \\
\hline Training (T1 or T2) $\times 5$-months & $\begin{array}{c}0.090 \\
(0.071)\end{array}$ & $\begin{array}{c}0.026 \\
(0.074)\end{array}$ & $\begin{array}{c}0.010 \\
(0.089)\end{array}$ & $\begin{array}{c}0.169 * * * \\
(0.054)\end{array}$ \\
\hline p-value (lags equal) & 0.89 & 0.87 & 0.79 & 0.31 \\
\hline Observations & 561 & 561 & 561 & 561 \\
\hline R-squared & 0.571 & 0.783 & 0.408 & 0.306 \\
\hline Mean Dep. Var. (C) & 0.580 & 0.746 & 0.694 & 0.767 \\
\hline
\end{tabular}

Notes: The table reports the coefficients for the effects of the training program on vendors' Awareness. Panel (A) reports the effects of belonging to any treatment group, i.e. $\beta$ in equation (3). Panel (B) shows the effects of the two treatment groups separately, i.e. $\beta_{1}$ and $\beta_{2}$ from equation (4). Finally, Panel (C) further distinguishes between treated vendors in terms of their workshop attendance timing, reporting the results from estimating specification (5). The rows document, for each outcome, the difference in that outcome exhibited by treated group compared to the control, for vendors whose last workshop attendance was 2, 3, 4, or 5, months before the endline survey. All regressions control for vendors' age, gender, education level, a binary indicator for stall ownership, years vending, area of vending, a binary indicator for food cooked at the stall, and the type of food, and include interviewer fixed effects. Robust standard errors, clustered at the block level, are in parentheses. These regressions are estimated only for the endline sample. $* p<0.10, * * 0<0.05, * * * p<0.01$.

to have taken, based on the endline data. According to Panel (A), vendors assigned to treatment are significantly more likely to have taken part in most of the activities they were asked about. Coefficients range from as large as $23 \%$ more for having tried to improve sanitation levels at their stalls, to a modest 6\% more for trying to obtain more information on the National Act. Similar to the results on awareness, Panel (B) shows that the effect for the two treatment arms are statistically 
indistinguishable from each other for all outcomes, with the exception of investing in stall equipment, for which vendors in the first treatment group in fact claim to have done more than those in the second group. Panel (C), grouping the treated vendors by the time elapsed since their last workshop, similarly demonstrates that, though the effect is strongest for the most recent attendees, it still persists for outcomes such as discussing food safety with other vendors and improving stall sanitation levels. The coefficients corresponding to all the lags are statistically indistinct from each other.

Table 6: Claimed Behaviors: Difference specification

\begin{tabular}{|c|c|c|c|c|c|c|c|c|}
\hline & $\begin{array}{c}\text { (1) } \\
\text { Discussions }\end{array}$ & $\begin{array}{c}(2) \\
\text { Get info }\end{array}$ & $\begin{array}{c}\text { (3) } \\
\text { Improvements }\end{array}$ & $\begin{array}{c}\text { (4) } \\
\text { investments }\end{array}$ & $\begin{array}{c}\text { (5) } \\
\text { Discuss NA }\end{array}$ & $\begin{array}{c}(6) \\
\text { Info on NA }\end{array}$ & $\begin{array}{c}\text { (7) } \\
\text { Unions }\end{array}$ & $\begin{array}{c}\text { (8) } \\
\text { Meetings }\end{array}$ \\
\hline & \multicolumn{8}{|c|}{ Panel (A): Unique Treatment } \\
\hline Training (T1 or $\mathrm{T} 2$ ) & $\begin{array}{c}0.204 * * * \\
(0.037)\end{array}$ & $\begin{array}{c}0.132^{* * *} \\
(0.038)\end{array}$ & $\begin{array}{c}0.230 * * * \\
(0.052)\end{array}$ & $\begin{array}{c}0.028 \\
(0.023)\end{array}$ & $\begin{array}{c}0.120 * * * \\
(0.032)\end{array}$ & $\begin{array}{l}0.060 * * \\
(0.029)\end{array}$ & $\begin{array}{c}0.002 \\
(0.020)\end{array}$ & $\begin{array}{c}0.090 * * * \\
(0.030)\end{array}$ \\
\hline Observations & 518 & 519 & 517 & 517 & 518 & 516 & 517 & 518 \\
\hline R-squared & 0.219 & 0.188 & 0.466 & 0.261 & 0.215 & 0.179 & 0.124 & 0.158 \\
\hline \multirow[t]{2}{*}{ Mean Dep. Var. (C) } & 0.049 & 0.068 & 0.270 & 0.062 & 0.031 & 0.062 & 0.043 & 0.037 \\
\hline & \multicolumn{8}{|c|}{ Panel (B): Separate Treatments } \\
\hline Training (T1) & $\begin{array}{c}0.225^{* * *} \\
(0.047)\end{array}$ & $\begin{array}{c}0.142 * * * \\
(0.048)\end{array}$ & $\begin{array}{c}0.213 * * * \\
(0.065)\end{array}$ & $\begin{array}{c}0.075^{* * *} * \\
(0.025)\end{array}$ & $\begin{array}{c}0.135^{* * * *} \\
(0.038)\end{array}$ & $\begin{array}{l}0.077 * * \\
(0.038)\end{array}$ & $\begin{array}{c}-0.007 \\
(0.025)\end{array}$ & $\begin{array}{l}0.086 * * \\
(0.035)\end{array}$ \\
\hline Training w/Signal (T2) & $\begin{array}{c}0.187 * * * \\
(0.044)\end{array}$ & $\begin{array}{l}0.124 * * * \\
(0.044)\end{array}$ & $\begin{array}{c}0.244 * * * \\
(0.054)\end{array}$ & $\begin{array}{l}-0.008 \\
(0.027)\end{array}$ & $\begin{array}{c}0.108 * * * \\
(0.037)\end{array}$ & $\begin{array}{c}0.047 \\
(0.033)\end{array}$ & $\begin{array}{c}0.008 \\
(0.025)\end{array}$ & $\begin{array}{l}0.094 * * \\
(0.037)\end{array}$ \\
\hline $\mathrm{p}$-value $(\mathrm{T} 1=\mathrm{T} 2)$ & 0.49 & 0.72 & 0.58 & 0.00 & 0.46 & 0.44 & 0.60 & 0.84 \\
\hline Observations & 518 & 519 & 517 & 517 & 518 & 516 & 517 & 518 \\
\hline R-squared & 0.220 & 0.188 & 0.467 & 0.276 & 0.216 & 0.181 & 0.125 & 0.158 \\
\hline \multirow[t]{2}{*}{ Mean Dep. Var. (C) } & 0.049 & 0.068 & 0.270 & 0.062 & 0.031 & 0.062 & 0.043 & 0.037 \\
\hline & \multicolumn{8}{|c|}{ Panel (C): Time-differentiated treatment } \\
\hline Training $(\mathrm{T} 1$ or $\mathrm{T} 2) \times 2$-months & $\begin{array}{l}0.219 * * \\
(0.093)\end{array}$ & $\begin{array}{l}0.133 * * \\
(0.059)\end{array}$ & $\begin{array}{c}0.250 * * * \\
(0.075)\end{array}$ & $\begin{array}{c}0.001 \\
(0.047)\end{array}$ & $\begin{array}{l}0.114 * * \\
(0.048)\end{array}$ & $\begin{array}{l}0.086 * \\
(0.049)\end{array}$ & $\begin{array}{c}0.022 \\
(0.035)\end{array}$ & $\begin{array}{c}0.067 \\
(0.059)\end{array}$ \\
\hline Training $(\mathrm{T} 1$ or $\mathrm{T} 2) \times 3$-months & $\begin{array}{c}0.211^{* * *} \\
(0.050)\end{array}$ & $\begin{array}{c}0.152 * * * \\
(0.050)\end{array}$ & $\begin{array}{c}0.229 * * * \\
(0.061)\end{array}$ & $\begin{array}{c}0.032 \\
(0.030)\end{array}$ & $\begin{array}{c}0.144 * * * \\
(0.038)\end{array}$ & $\begin{array}{l}0.063 * \\
(0.037)\end{array}$ & $\begin{array}{c}-0.007 \\
(0.025)\end{array}$ & $\begin{array}{c}0.113 * * * \\
(0.036)\end{array}$ \\
\hline Training $(\mathrm{T} 1$ or $\mathrm{T} 2) \times 4$-months & $\begin{array}{c}0.091 \\
(0.059)\end{array}$ & $\begin{array}{c}0.087 \\
(0.058)\end{array}$ & $\begin{array}{l}0.174 * * \\
(0.068)\end{array}$ & $\begin{array}{c}0.007 \\
(0.026)\end{array}$ & $\begin{array}{l}0.070 * \\
(0.042)\end{array}$ & $\begin{array}{c}0.039 \\
(0.046)\end{array}$ & $\begin{array}{c}-0.009 \\
(0.021)\end{array}$ & $\begin{array}{c}0.040 \\
(0.035)\end{array}$ \\
\hline Training $(\mathrm{T} 1$ or $\mathrm{T} 2) \times 5$-months & $\begin{array}{l}0.244 * * \\
(0.103)\end{array}$ & $\begin{array}{c}0.130 \\
(0.082)\end{array}$ & $\begin{array}{l}0.211^{* *} \\
(0.094)\end{array}$ & $\begin{array}{c}0.004 \\
(0.050)\end{array}$ & $\begin{array}{c}0.100 \\
(0.077)\end{array}$ & $\begin{array}{c}0.065 \\
(0.060)\end{array}$ & $\begin{array}{c}0.042 \\
(0.075)\end{array}$ & $\begin{array}{c}0.117 \\
(0.074)\end{array}$ \\
\hline p-value (lags equal) & 0.23 & 0.80 & 0.81 & 0.79 & 0.43 & 0.87 & 0.75 & 0.16 \\
\hline Observations & 518 & 519 & 517 & 517 & 518 & 516 & 517 & 518 \\
\hline R-squared & 0.222 & 0.192 & 0.465 & 0.261 & 0.221 & 0.181 & 0.127 & 0.164 \\
\hline Mean Dep. Var. (C) & 0.049 & 0.068 & 0.270 & 0.062 & 0.031 & 0.062 & 0.043 & 0.037 \\
\hline
\end{tabular}

Notes: The table reports the coefficients for the effects of the training program on vendors' Claimed Behavior. Panel (A) reports the effects of belonging to any treatment group, i.e. $\beta$ in equation (3). Panel (B) shows the effects of the two treatment groups separately, i.e. $\beta_{1}$ and $\beta_{2}$ from equation (4). Finally, Panel (C) further distinguishes between treated vendors in terms of their workshop attendance timing, reporting the results from estimating specification (5). The rows document, for each outcome, the difference in that outcome exhibited by treated group compared to the control, for vendors whose last workshop attendance was 2, 3, 4, or 5, months before the endline survey. All regressions control for vendors' age, gender, education level, a binary indicator for stall ownership, years vending, area of vending, a binary indicator for food cooked at the stall, and the type of food, and include interviewer fixed effects. Robust standard errors, clustered at the block level, are in parentheses. These regressions are estimated only for the endline sample. ${ }^{*} p<0.10, * * p<0.05, * * * p<0.01$.

Third, regarding Observed behavior, we estimate specification (6), which gives us the differencein-difference estimate of the effect of training on treatment blocks, comparing their outcomes be- 
fore and after they have attended the workshops to those with control blocks at the same point of time. Table 7 presents these results. The three panels correspond to the three workshops, and Training $\times$ post workshop is an indicator for the vendor being assigned to treatment and monitoring occurring post the intended (or scheduled) date of each workshop, irrespective of whether they actually attended. The empirical analysis yields (i) A robust positive estimate of the effect of the training on the facilities index (3.9\% after the third workshop, or $8.7 \%$ of the mean control group) and (ii) A positive effect on the total index (2.7\%, or $4.6 \%$ of the mean control group). Furthermore, Table 8 reports the results for the 2 treatments separately. As one can see, and much to the opposite with respect to our expectations, the estimated effect is driven by the T1 group. Indeed the signal tools provided to vendors, not only they do not provide an additional positive effect, but actually they make things worst. One may argue that there seems to be a substitution between effort and advertising: When vendors are provided with promotional material, they may feel that they already signal their quality to consumers and stop making efforts to prove that their food is safe. Nevertheless we leave further investigation of this empirical evidence for future research. Overall, although there is some effect of the training, we argue that the magnitude is only modest and does not allow us to conclude that a cheap intervention such as ours can alone sustain a marked improvement in food safety behaviors.

We run several robustness checks to further explore the effects of the training on actual behavior. First, in order to explore the possible heterogeneity of time, we estimate the same differencein-difference specification as in (6) by further splitting the treated vendors by the amount of time elapsed since each workshop. Appendix Table A.1 reports these results. Unfortunately, no conclusive results emerge from the analysis. ${ }^{23}$ Second, in order to explore the possible heterogeneity of the training with respect to the type of business ran on the street, we restrict the analysis to the group of vendors that might benefit the most from the workshops: vendors selling cooked food on the street. The results are qualitatively similar to the ones reported in the text and are available upon request. Third, we use the information of the networks that the vendors operate in, to explore whether the effects of the training are exacerbated by peer effects. From the location of each block,

\footnotetext{
${ }^{23}$ Notice that we observe some swinging in the time that the effect of the training takes shape, with the training sometimes only taking effect once the vendors have had more time to absorb the new information and implement it. In order to deal with this, in our comparison of the effects on the two treatment groups, we rerun specification (3) for all three outcomes controlling for the amount of time elapsed since the vendor had their first workshop. Since our aim here is to only get a comparison between the two treatment groups, we estimate these regressions only off the treated sample. The results are reported in Table A.5 of the Appendix. We find that while the vendors who were provided with the opportunity to signal do in fact perform better on the awareness front, the first treatment group exhibits statistically similar, or even marginally better, outcomes in terms of both claimed and actual behavior.
} 
Table 7: Observed Behavior: Difference-Difference specification

\begin{tabular}{|c|c|c|c|c|}
\hline & $\begin{array}{l}\text { (1) } \\
\text { Facilities } \\
\text { Index }\end{array}$ & $\begin{array}{l}\text { (2) } \\
\text { Food handling } \\
\text { Index }\end{array}$ & $\begin{array}{l}\text { (3) } \\
\text { Customer care } \\
\text { Index }\end{array}$ & $\begin{array}{c}(4) \\
\text { Total } \\
\text { Index }\end{array}$ \\
\hline & \multicolumn{4}{|c|}{ Panel (A): Workshop 1} \\
\hline Training $(\mathrm{T} 1$ or $\mathrm{T} 2) \times$ post workshop & $\begin{array}{l}0.018 * \\
(0.010)\end{array}$ & $\begin{array}{c}0.000 \\
(0.013)\end{array}$ & $\begin{array}{l}-0.002 \\
(0.020)\end{array}$ & $\begin{array}{c}0.003 \\
(0.010)\end{array}$ \\
\hline Observations & 3,478 & 2,648 & 3,201 & 3,478 \\
\hline R-squared & 0.174 & 0.189 & 0.354 & 0.227 \\
\hline \multirow[t]{2}{*}{ Mean Dep. Var. (C) } & 0.447 & 0.694 & 0.689 & 0.581 \\
\hline & \multicolumn{4}{|c|}{ Panel (B): Workshop 2} \\
\hline Training $(\mathrm{T} 1$ or $\mathrm{T} 2) \times$ post workshop & $\begin{array}{l}0.026^{* * *} \\
(0.012)\end{array}$ & $\begin{array}{l}-0.006 \\
(0.012)\end{array}$ & $\begin{array}{c}0.004 \\
(0.019)\end{array}$ & $\begin{array}{c}0.007 \\
(0.011)\end{array}$ \\
\hline $\begin{array}{l}\text { Observations } \\
\text { R-squared } \\
\text { Mean Dep. Var. (C) }\end{array}$ & $\begin{array}{l}3,478 \\
0.175 \\
0.447\end{array}$ & $\begin{array}{l}2,648 \\
0.189 \\
0.694\end{array}$ & $\begin{array}{l}3,201 \\
0.354 \\
0.689\end{array}$ & $\begin{array}{l}3,478 \\
0.227 \\
0.581\end{array}$ \\
\hline Mean Dep. Var. (C) & \multicolumn{4}{|c|}{ Panel (C): Workshop 3} \\
\hline Training $(\mathrm{T} 1$ or $\mathrm{T} 2) \times$ post workshop & $\begin{array}{l}0.039 * * \\
(0.015)\end{array}$ & $\begin{array}{l}-0.022 \\
(0.014)\end{array}$ & $\begin{array}{c}0.024 \\
(0.021)\end{array}$ & $\begin{array}{l}0.027 * \\
(0.015)\end{array}$ \\
\hline $\begin{array}{l}\text { Observations } \\
\text { R-squared } \\
\text { Mean Dep. Var. (C) }\end{array}$ & $\begin{array}{l}3,478 \\
0.176 \\
0.447\end{array}$ & $\begin{array}{l}2,648 \\
0.190 \\
0.694\end{array}$ & $\begin{array}{l}3,201 \\
0.355 \\
0.689\end{array}$ & $\begin{array}{l}3,478 \\
0.229 \\
0.581\end{array}$ \\
\hline \multicolumn{5}{|c|}{$\begin{array}{l}\text { Notes: The table reports the coefficients for the effects of the training program on vendors' Observed Behavior. We } \\
\text { estimate specification (6), which gives us the difference-in-difference estimate of the effect of training on treatment } \\
\text { blocks, comparing their outcomes before and after they have attended the workshops to those with control blocks } \\
\text { at the same point of time. The three panels correspond to the three workshops, and } T \times \text { post workshop is an } \\
\text { indicator for the vendor being assigned to treatment and monitoring occurring post the intended (or scheduled) } \\
\text { date of each workshop, irrespective of whether they actually attended. All regressions control for vendors' age, } \\
\text { gender, education level, a binary indicator for stall ownership, years vending, area of vending, a binary indicator } \\
\text { for food cooked at the stall, and the type of food, and include interviewer fixed effects. Robust standard errors, } \\
\text { clustered at the block level, are in parentheses. These regressions are estimated using all the } 6 \text { survey rounds. } \\
{ }^{*} p<0.10, * * p<0.05, * * * p<0.01 \text {. }\end{array}$} \\
\hline
\end{tabular}

we know which two blocks are its closest neighbors in terms of geographical distance. Since the analysis does not lead to any new insight, we report the results in the Appendix A.2. Finally, we estimate some alternative specifications as additional robustness tests. We estimate the effect of the training by using the assignment of vendors to a treatment group as an instrument for receiving the training. We estimate a specification identical to (3), but also controlling for the baseline levels of the outcome variables, off the data collected from the first monitoring period onwards. In both cases, the results are qualitatively identical to the Diff-in-Diff specifications and available upon request. $^{24}$

\footnotetext{
${ }^{24}$ Interestingly, we observe an increase in the observed behavioral outcomes from the baseline to the endline across both treated and control groups. For instance, the Total Index goes up to from 0.58 (in Table 3) to 0.63 (in Table 4). A possible explanation would be that vendors changed their behavior because of the monitoring, which could explain the improvement also among vendors in the control group. This improvement should therefore depend upon the frequency of the monitoring. To discard this hypothesis, we test whether vendors monitored more times show better performances. The results, available upon request, do not highlight any evidence in favor of this hypothesis.
} 
Table 8: Observed Behavior: Difference-Difference specification with separate treatments

\begin{tabular}{|c|c|c|c|c|}
\hline & $\begin{array}{l}\quad(1) \\
\text { Facilities } \\
\text { Index }\end{array}$ & $\begin{array}{l}(2) \\
\text { Food handling } \\
\text { Index }\end{array}$ & $\begin{array}{l}\text { (3) } \\
\text { Customer care } \\
\text { Index }\end{array}$ & $\begin{array}{c}(4) \\
\text { Total } \\
\text { Index }\end{array}$ \\
\hline & \multicolumn{4}{|c|}{ Panel (A): Workshop 1} \\
\hline Training $(\mathrm{T} 1) \times$ post workshop & $\begin{array}{l}0.033 * * \\
(0.016)\end{array}$ & $\begin{array}{c}-0.009 \\
(0.018)\end{array}$ & $\begin{array}{c}0.024 \\
(0.027)\end{array}$ & $\begin{array}{c}0.015 \\
(0.012)\end{array}$ \\
\hline Training w/Signal $($ T2) $\times$ post workshop & $\begin{array}{c}-0.007 \\
(0.012)\end{array}$ & $\begin{array}{c}-0.002 \\
(0.015)\end{array}$ & $\begin{array}{c}-0.025 \\
(0.026)\end{array}$ & $\begin{array}{l}-0.020 \\
(0.013)\end{array}$ \\
\hline $\begin{array}{l}\text { Observations } \\
\text { R-squared } \\
\text { Mean Dep. Var. (C) }\end{array}$ & $\begin{array}{l}3,478 \\
0.177 \\
0.447\end{array}$ & $\begin{array}{l}2,648 \\
0.191 \\
0.694\end{array}$ & $\begin{array}{l}3,201 \\
0.355 \\
0.689\end{array}$ & $\begin{array}{l}3,478 \\
0.231 \\
0.581\end{array}$ \\
\hline Mean Dep. Var. (C) & \multicolumn{4}{|c|}{ Panel (B): Workshop 2} \\
\hline Training $(\mathrm{T} 1) \times$ post workshop & $\begin{array}{l}0.034 * * \\
(0.016)\end{array}$ & $\begin{array}{l}-0.026 \\
(0.017)\end{array}$ & $\begin{array}{c}0.029 \\
(0.026)\end{array}$ & $\begin{array}{c}0.012 \\
(0.012)\end{array}$ \\
\hline Training w/Signal $(\mathrm{T} 2) \times$ post workshop & $\begin{array}{c}0.003 \\
(0.016)\end{array}$ & $\begin{array}{c}0.002 \\
(0.015)\end{array}$ & $\begin{array}{c}-0.020 \\
(0.024)\end{array}$ & $\begin{array}{c}-0.015 \\
(0.017)\end{array}$ \\
\hline $\begin{array}{l}\text { Observations } \\
\text { R-squared } \\
\text { Mean Dep. Var. (C) }\end{array}$ & $\begin{array}{l}3,478 \\
0.177 \\
0.447\end{array}$ & $\begin{array}{l}2,648 \\
0.191 \\
0.694\end{array}$ & $\begin{array}{l}3,201 \\
0.355 \\
0.689\end{array}$ & $\begin{array}{l}3,478 \\
0.230 \\
0.581\end{array}$ \\
\hline Mean Dep. Var. (C) & \multicolumn{4}{|c|}{ Panel (C): Workshop 3} \\
\hline Training $(\mathrm{T} 1) \times$ post workshop & $\begin{array}{l}0.034 * * \\
(0.015)\end{array}$ & $\begin{array}{c}-0.032^{* *} \\
(0.015)\end{array}$ & $\begin{array}{c}0.040 \\
(0.028)\end{array}$ & $\begin{array}{l}0.023 * \\
(0.013)\end{array}$ \\
\hline Training w/Signal $(\mathrm{T} 2) \times$ post workshop & $\begin{array}{c}0.029 \\
(0.026)\end{array}$ & $\begin{array}{l}-0.041 * \\
(0.024)\end{array}$ & $\begin{array}{c}0.003 \\
(0.029)\end{array}$ & $\begin{array}{c}0.010 \\
(0.023)\end{array}$ \\
\hline $\begin{array}{l}\text { Observations } \\
\text { R-squared } \\
\text { Mean Dep. Var. (C) }\end{array}$ & $\begin{array}{l}3,478 \\
0.176 \\
0.447\end{array}$ & $\begin{array}{l}2,648 \\
0.190 \\
0.694\end{array}$ & $\begin{array}{l}3,201 \\
0.355 \\
0.689\end{array}$ & $\begin{array}{l}3,478 \\
0.229 \\
0.581\end{array}$ \\
\hline $\begin{array}{l}\text { Notes: The table reports the coefficients for the e } \\
\text { estimate specification (6), which gives us the diffe } \\
\text { blocks, comparing their outcomes before and after } \\
\text { the same point of time. The three panels correspo } \\
\text { for the vendor being assigned to treatment and mo } \\
\text { workshop, irrespective of whether they actually att } \\
\text { level, a binary indicator for stall ownership, years } \\
\text { stall, and the type of food, and include interviewer }\end{array}$ & $\begin{array}{l}\text { nce-in-differ } \\
\text { ley have att } \\
\text { to the thre } \\
\text { itoring occu } \\
\text { ded. All rey } \\
\text { nding, area }\end{array}$ & $\begin{array}{l}\text { ining program on } \\
\text { nce estimate of th } \\
\text { ided the workshop } \\
\text { workshops, and } T \\
\text { ing post the inten } \\
\text { essions control for } \\
\text { vending, a binary }\end{array}$ & $\begin{array}{l}\text { vendors' Observed } B \\
\text { effect of training c } \\
\text { s to those with cont } \\
\times \text { post workshop is } \\
\text { ded (or scheduled) } \\
\text { vendors' age, gende } \\
\text { indicator for food c } \\
\text { ors, clustered at the }\end{array}$ & $\begin{array}{l}\text { havior. We } \\
\text { treatment } \\
\text { l blocks at } \\
\text { n indicator } \\
\text { ate of each } \\
\text { education } \\
\text { ked at the } \\
\text { lock level, }\end{array}$ \\
\hline
\end{tabular}

\subsection{Why are behavioral improvements difficult to undertake?}

As discussed thus far, the training had only a modest effect on vendors' actual behavior, despite the marked improvement in awareness and claimed actions taken. Based on the simple model outlined in Section 2.2, this result may be explained by the fact that (i) Informational trainings do not translate into a reduction of vendors' expected costs and uncertainty to produce $H$, and (ii) Informational devices to advertise the participation into such trainings do not translate into an increase in expected revenues. To put it another way, simple informational shocks do not make the production of $H$ more profitable and hence they are not enough to boost an increase in the 
quality of goods in the market. In this section, we aim to provide some direct evidence against our assumptions of Section 2.2, which in turn may help providing some concrete explanations for our negative findings.

First, concerning the supply side of the market, the assumption that an informational training about food quality and hygienic practices lowers the costs of production, may be weak. In order to test for it directly, we collected a set of direct questions aimed at capturing the vendors' own assessment of the resources needed to make behavioral improvements. During the baseline and the endline surveys, vendors were asked how "costly" they thought it was for them to make the following changes in their stalls: (i) Provide clean drinking water; (ii) Maintain a dustbin that was emptied regularly; (iii) Use a clean cloth to wipe their hands; (iv) To keep the cooking area clean and free of food debris; and (v) To use disposable plates and cups. The vendors could rate the difficulty level of making these improvements, on an ordinal scale of very easy (1) to very difficult (5). Note that since we are only comparing the answers of the same vendors from the baseline and the endline, it is not a problem for our purposes if all vendors did not have the same interpretation of the difficulty levels, as long as the interpretation was consistent over time.

Table 9 shows that the training has the expected negative sign on all the dependent variables, but the effect is almost never significant. That is, the workshops does not significantly reduce how costly the vendors think it is to adopt these practices, despite improving their awareness about them. ${ }^{25}$ The result confirms that vendors might not have had the sufficient stimulus to alter their behavior, notwithstanding the marked improvement in awareness. We conclude that, indeed, providing information is not a sufficient condition to substantially decrease the perceived cost of tackling food safety hazards. ${ }^{26}$

Second, concerning the demand side of the market, the assumption that consumers have a stronger taste for high-quality food (or equivalently that they sufficiently care about the level of hygienic practices adopted by the vendors), may also be problematic. This would imply that vendors may not have enough incentives to alter their practices in order to retain their customer base. This fact would also be in line with the result that providing promotional material has not been effective

\footnotetext{
${ }^{25} \mathrm{~A}$ series of questions in the baseline had sough to identify what the vendors considered the greatest problems in running their business (such as unavailability of running water, persecution by the local authorities etc) which hinted at different non-economic costs of altering their behavior. As a further robustness test, we separately examine how the perceived cost changed for vendors who identified no threats to their business and those that identified multiple threats, and find no significant improvement for either group.

${ }^{26}$ Notice that one could interpret these results as showing that the training just provided a clearer idea about the costs. However, the negative sign of most of these effects suggests that the training works in our direction, but it was not sufficiently strong to lower the other "costs of production" for the vendors.
} 
Table 9: How "costly" is to make the following changes in the stalls?

\begin{tabular}{|c|c|c|c|c|c|}
\hline & $\begin{array}{c}\text { (1) } \\
\text { Clean water }\end{array}$ & $\begin{array}{c}\text { (2) } \\
\text { Dustbin }\end{array}$ & $\begin{array}{l}\text { (3) } \\
\text { Clean cloths }\end{array}$ & $\begin{array}{c}\text { (4) } \\
\text { Cooking area }\end{array}$ & $\begin{array}{c}(5) \\
\text { Disposable cups }\end{array}$ \\
\hline & \multicolumn{5}{|c|}{ Panel (A): Unique Treatment } \\
\hline Training $(\mathrm{T} 1$ or $\mathrm{T} 2) \times$ Endline & $\begin{array}{l}-0.014 \\
(0.152)\end{array}$ & $\begin{array}{l}-0.033 \\
(0.100)\end{array}$ & $\begin{array}{l}-0.139 \\
(0.104)\end{array}$ & $\begin{array}{l}-0.023 \\
(0.119)\end{array}$ & $\begin{array}{l}-0.163 \\
(0.143)\end{array}$ \\
\hline Observations & 1,242 & 1,242 & 1,242 & 1,242 & 1,242 \\
\hline R-squared & 0.274 & 0.408 & 0.414 & 0.380 & 0.331 \\
\hline \multirow[t]{2}{*}{ Mean Dep. Var. (C) } & 2.981 & 3.394 & 3.565 & 3.472 & 2.924 \\
\hline & \multicolumn{5}{|c|}{ Panel (B): Separate Treatments } \\
\hline Training $(\mathrm{T} 1) \times$ Endline & $\begin{array}{c}-0.134 \\
(0.174)\end{array}$ & $\begin{array}{c}-0.065 \\
(0.116)\end{array}$ & $\begin{array}{l}-0.207 * \\
(0.119)\end{array}$ & $\begin{array}{c}-0.101 \\
(0.124)\end{array}$ & $\begin{array}{c}-0.200 \\
(0.166)\end{array}$ \\
\hline Training w/Signal $(\mathrm{T} 2) \times$ Endline & $\begin{array}{c}0.087 \\
(0.174)\end{array}$ & $\begin{array}{l}-0.005 \\
(0.118)\end{array}$ & $\begin{array}{l}-0.085 \\
(0.111)\end{array}$ & $\begin{array}{c}0.039 \\
(0.133)\end{array}$ & $\begin{array}{l}-0.129 \\
(0.163)\end{array}$ \\
\hline $\mathrm{p}$-value $(\mathrm{T} 1=\mathrm{T} 2)$ & 0.203 & 0.622 & 0.210 & 0.167 & 0.668 \\
\hline Observations & 1,242 & 1,242 & 1,242 & 1,242 & 1,242 \\
\hline R-squared & 0.280 & 0.409 & 0.415 & 0.381 & 0.334 \\
\hline \multirow[t]{2}{*}{ Mean Dep. Var. (C) } & 2.981 & 3.394 & 3.565 & 3.472 & 2.924 \\
\hline & \multicolumn{5}{|c|}{ Panel (C): Vendors Reporting Problems } \\
\hline Training $(\mathrm{T} 1$ or $\mathrm{T} 2) \times$ Endline & $\begin{array}{c}0.010 \\
(0.157)\end{array}$ & $\begin{array}{c}0.018 \\
(0.107)\end{array}$ & $\begin{array}{c}-0.129 \\
(0.113)\end{array}$ & $\begin{array}{c}-0.018 \\
(0.124)\end{array}$ & $\begin{array}{c}-0.147 \\
(0.157)\end{array}$ \\
\hline Observations & 1,049 & 1,049 & 1,049 & 1,049 & 1,049 \\
\hline R-squared & 0.283 & 0.404 & 0.425 & 0.387 & 0.362 \\
\hline \multirow[t]{2}{*}{ Mean Dep. Var. (C) } & 2.928 & 3.376 & 3.521 & 3.467 & 2.829 \\
\hline & \multicolumn{5}{|c|}{ Panel D: Vendors Reporting No Problems } \\
\hline Training $(\mathrm{T} 1$ or $\mathrm{T} 2) \times$ Endline & $\begin{array}{l}-0.115 \\
(0.400)\end{array}$ & $\begin{array}{l}-0.319 \\
(0.233)\end{array}$ & $\begin{array}{l}-0.225 \\
(0.179)\end{array}$ & $\begin{array}{l}-0.153 \\
(0.228)\end{array}$ & $\begin{array}{c}0.269 \\
(0.347)\end{array}$ \\
\hline Observations & 193 & 193 & 193 & 193 & 193 \\
\hline R-squared & 0.424 & 0.585 & 0.503 & 0.460 & 0.458 \\
\hline Mean Dep. Var. (C) & 3.254 & 3.459 & 3.795 & 3.533 & 3.000 \\
\hline
\end{tabular}

Notes: During the baseline and the endline surveys, vendors were asked how "costly" they thought it was for them to make the following changes in their stalls: (i) Provide clean drinking water; (ii) Maintain a dustbin that was emptied regularly; (iii) Use a clean cloth to wipe their hands; (iv) To keep the cooking area clean and free of food debris; and (v) To use disposable plates and cups. All regressions control for vendors' age, gender, education level, a binary indicator for stall ownership, years vending, area of vending, a binary indicator for food cooked at the stall, and the type of food, and include interviewer fixed effects. Robust standard errors, clustered at the block level, are in parentheses. These regressions are estimated only for the endline sample. ${ }^{*} p<0.10$, $* * p<0.05, * * * p<0.01$.

in prompting a stronger change among vendors in T2. In fact, as highlighted in the previous section, for most outcomes we have shown that the effect of the training is similar between T1 and T2. In a similar vein, the demand in this sector is perhaps quite price-elastic but quality inelastic. This means that the consumers' willingness to pay for the food does not really respond to the perceived quality, but their demand drops sharply if the price increases.

In order to provide some suggestive evidence that consumers may not have such a higher willingness to pay for $H$, we obtained business information such as profits, revenues and prices of the 
Table 10: Business information

\begin{tabular}{|c|c|c|c|c|}
\hline & $\begin{array}{c}\text { (1) } \\
\text { Revenues }\end{array}$ & $\begin{array}{c}(2) \\
\text { Profits }\end{array}$ & $\begin{array}{c}\text { (3) } \\
\text { Expenditures }\end{array}$ & $\begin{array}{l}(4) \\
\text { Price }\end{array}$ \\
\hline & \multicolumn{4}{|c|}{ Panel (A): Unique Treatment } \\
\hline Training $(\mathrm{T} 1$ or $\mathrm{T} 2) \times$ endline & $\begin{array}{c}-71.8 \\
(121.7)\end{array}$ & $\begin{array}{l}-17.5 \\
(33.3)\end{array}$ & $\begin{array}{c}-54.3 \\
(100.4)\end{array}$ & $\begin{array}{l}2.1^{*} \\
(1.2)\end{array}$ \\
\hline $\begin{array}{l}\text { Observations } \\
\text { R-squared } \\
\text { Mean Dep. Var. (C) }\end{array}$ & $\begin{array}{l}1,108 \\
0.266 \\
1378 \\
\end{array}$ & $\begin{array}{c}1,108 \\
0.148 \\
334 \\
\end{array}$ & $\begin{array}{l}1,108 \\
0.264 \\
1044 \\
\end{array}$ & $\begin{array}{c}1,228 \\
0.421 \\
16 \\
\end{array}$ \\
\hline Mean Dep. Var. (C) & \multicolumn{4}{|c|}{ Panel (B): Separate Treatments } \\
\hline Training $(\mathrm{T} 1) \times$ endline & $\begin{array}{c}-47.8 \\
(135.8)\end{array}$ & $\begin{array}{c}13.2 \\
(40.5)\end{array}$ & $\begin{array}{c}-61.0 \\
(107.1)\end{array}$ & $\begin{array}{c}2.1 \\
(1.4)\end{array}$ \\
\hline Training w/Signal $(\mathrm{T} 2) \times$ endline & $\begin{array}{c}-87.9 \\
(147.2)\end{array}$ & $\begin{array}{l}-43.8 \\
(32.9)\end{array}$ & $\begin{array}{c}-44.1 \\
(127.4)\end{array}$ & $\begin{array}{c}2.2 \\
(1.4)\end{array}$ \\
\hline $\begin{array}{l}\text { Observations } \\
\text { R-squared } \\
\text { Mean Dep. Var. (C) }\end{array}$ & $\begin{array}{l}1,108 \\
0.267 \\
1378\end{array}$ & $\begin{array}{c}1,108 \\
0.150 \\
334\end{array}$ & $\begin{array}{l}1,108 \\
0.265 \\
1044\end{array}$ & $\begin{array}{c}1,228 \\
0.427 \\
16\end{array}$ \\
\hline Mean Dep. Var. (C) & \multicolumn{4}{|c|}{ Panel (C): Improving Vendors Only } \\
\hline Training $(\mathrm{T} 1) \times$ endline & $\begin{array}{c}-41.7 \\
(164.3)\end{array}$ & $\begin{array}{c}-8.4 \\
(56.8)\end{array}$ & $\begin{array}{c}-33.3 \\
(132.3)\end{array}$ & $\begin{array}{c}2.2 \\
(1.9)\end{array}$ \\
\hline Training w/Signal $(\mathrm{T} 2) \times$ endline & $\begin{array}{l}-111.3 \\
(169.1) \\
(169.1)\end{array}$ & $\begin{array}{l}-49.1 \\
(46.9) \\
(46.9)\end{array}$ & $\begin{array}{c}-62.3 \\
(149.4) \\
(149.3)\end{array}$ & $\begin{array}{c}0.9 \\
(2.3) \\
(2.3)\end{array}$ \\
\hline Observations & 588 & 588 & 588 & 655 \\
\hline R-squared & 0.327 & 0.172 & 0.327 & 0.407 \\
\hline Mean Dep. Var. (C) & 1389 & 349 & 1041 & 16 \\
\hline
\end{tabular}

Notes: The table reports the coefficients for the effects of the training program on vendors' profits and revenues. We estimate a Difference-in-Difference specification, based on observed profits/revenues at the baseline and at the endline surveys. Panel (A) reports the effects of belonging to any treatment group. Panel (B) shows the effects of the two treatment groups separately. Finally, Panel (C) restricts the sample to vendors whose behavior improved during the endline compared to the baseline. All regressions control for vendors' age, gender, education level, a binary indicator for stall ownership, years vending, area of vending, a binary indicator for food cooked at the stall, and the type of food, and include interviewer fixed effects. Robust standard errors, clustered at the block level, are in parentheses. $* \mathrm{p}<0.10, * * \mathrm{p}<0.05, * * \mathrm{p}<0.01$

main dish sold, both during the baseline and the endline. This allows us to explore whether there was an improvement in these variables for treated vendors at the endline compared to the beginning of the study. Table 10 reports the results. The treated vendors exhibit no change in their total revenue or in their profits, including the subgroup that can signal their participation to the workshops. Of course, this has a possibility of reverse causality: the sales and profits of the vendors are not improving precisely because they are unable to improve their food handling practices. To rule this out, we restrict our analysis to vendors whose behavior improved during the endline compared to the 
baseline. ${ }^{27}$ To the extent that the vendors endogenously adjust their behavior only if they believe that this would translate into better business outcomes, this subgroup is selected to demonstrate a differentially higher increase in their prices, sales and profits. However, we find no such improvements even for this group of vendors. Although this test does not provide conclusive evidence, it suggests that, indeed, improving food safety may not meet a higher demand from customers.

\section{Conclusion and Policy Implications}

In this paper, we implement a randomized control trial to test whether a cheap intervention aimed at increasing food safety awareness among street vendors, can improve food safety behaviors on the street. We select a sample of 681 street-food vendors from Kolkata, India, and randomly allocated a fraction of them to receive a training program. The training consisted of 3 workshops and 3 followups, organized in 10 consecutive weeks, and had two aims: first, to enhance vendors' awareness of health risks related to food vending, and second, to develop their capacity to make the necessary improvements in food safety practices. In our design, half of the vendors who were assigned to the training received also promotional material, specifically tailored posters, napkins and certificates, allowing them to advertise to customers their participation to the program. We monitor vendors' behaviors both through standard survey questions and external monitoring of their daily behaviors, an objective measure of their performance.

Overall, we find substantial improvements in vendors' awareness, knowledge about food safety hazards and claimed actions taken. However, we observe limited effects on vendors' actual behaviors, as measured by external monitoring. Our design allows us to investigate three possible explanations regarding the results on behavior: i) Food safety improvements are not undertaken because they go unnoticed by consumers; ii) The cost of improving food safety might be too high in this sector and it is not lowered by the training; iii) Costumers' willingness to pay for safer street food might simply be scarce. While we do not find evidence in favor of the first explanation, as vendors equipped with promotional material do not improve their behavior differently, we provide suggestive evidence that (i) vendors' perceived cost of improving food safety is unchanged after the training, and (ii) lack of demand for safer foods is also a likely driver of the results. Both factors are in line with the hypothesis that hard cost of production and uncertainty of demand are limiting

\footnotetext{
${ }^{27}$ Here, we consider improvement in terms of the total index of behavior.
} 
for self-improvement (or self-regulation) in food safety in this informal sector.

While our results highlight that information alone is not sufficient to alter hygienic practices in this sector, they allow us to point out that future research, as well as policy making, should focus on both demand and supply-side factors in order to obtain improvements in street-food vending sector. First, lack of basic facilities, such as clean water, waste disposal and electricity, are all underlying constraints limiting self-improvement in food safety, and should be at the core of investigation in future studies. Second, customers might be accustomed to the current street-food hygienic standards, therefore policy making should also focus on increasing food safety awareness among customers. 


\section{References}

Abushelaibi, A. M., B. Jobe, H. S. Afifi, B.-E. Mostafa, A. A. Murad, And A. K. Mohammed (2015): "Evaluation of the effect of person-in-charge (PIC) program on knowledge and practice change of food handlers in Dubai," Food Control, 50, 382-392.

Argent, J., B. Augsburg, AND I. RAsul (2014): "Livestock asset transfers with and without training: Evidence from Rwanda," Journal of Economic Behavior \& Organization, 108, 19-39.

Ashraf, N., E. FIELD, AND J. LEE (2014): "Household bargaining and excess fertility: an experimental study in Zambia," The American Economic Review, 104, 2210-2237.

BAnerJee, A., S. BARnhardt, E. Duflo, Et Al. (2015): "Movies, Margins, and Marketing: Encouraging the Adoption of Iron-Fortified Salt," NBER Chapters.

BARON, D. P. (2009): "A positive theory of moral management, social pressure, and corporate social performance," Journal of Economics \& Management Strategy, 18, 7-43.

(2010): "Morally motivated self-regulation," The American Economic Review, 100, 12991329.

BARon, D. P. AND D. Diermeier (2007): "Strategic activism and nonmarket strategy," Journal of Economics \& Management Strategy, 16, 599-634.

BHowmik, S. (2012): Street vendors in the global urban economy, Taylor \& Francis.

BRomley, R. (2000): "Street vending and public policy: a global review," International Journal of Sociology and Social Policy, 20, 1-28.

Brooks, W., K. Donovan, And T. R. Johnson (2018): "Mentors or Teachers? Microenterprise Training in Kenya," American Economic Journal: Applied Economics (Forthcoming).

CASAburi, L. AND R. MAcChiavello (2015): "Loyalty, Exit, and Enforcement: Evidence from a Kenya Dairy Cooperative," American Economic Review, 105, 286-90.

Chakravarty, I. And C. CANet (1996): "Street foods in Calcutta," Food, Nutrition and Agriculture, 29, 30-37.

Choudhury, M., L. B. Mahanta, J. S. Goswami, And M. D. Mazumder (2011): "Will capacity building training interventions given to street food vendors give us safer food?: A cross-sectional study from India," Food Control, 22, 1233-1239.

Cortese, R. D. M., M. B. Veiros, C. Feldman, and S. B. Cavalli (2016): "Food safety and hygiene practices of vendors during the chain of street food production in Florianopolis, Brazil: A crosssectional study," Food control, 62, 178-186.

DA Cunha, D. T., E. StedefeldT, And V. V. DE Rosso (2014): "The role of theoretical food safety training on Brazilian food handlers' knowledge, attitude and practice," Food Control, 43, 167174.

De Mel, S., D. McKenzie, And C. Woodruff (2014): "Business training and female enterprise start-up, growth, and dynamics: Experimental evidence from Sri Lanka," Journal of Development Economics, 106, 199-210.

Duflo, E., P. Dupas, AND M. Kremer (2015): "Education, HIV, and early fertility: Experimental evidence from Kenya," The American economic review, 105, 2757-2797. 
Duflo, E., S. GAliani, AND M. Mobarak (2012): "Improving access to urban services for the poor: open issues and a framework for a future research agenda," J-PAL Urban Services Review Paper. Cambridge, MA: Abdul Latif Jameel Poverty Action Lab. http://www. povertyactionlab. org/publication/improving-access-urban-services-poor.

DUPAS, P. (2011): "Do teenagers respond to HIV risk information? Evidence from a field experiment in Kenya," American Economic Journal: Applied Economics, 3, 1-34.

DuPAS, P. AND E. Miguel (2017): "Impacts and determinants of health levels in low-income countries," Handbook of Economic Field Experiments, 2, 3-93.

FAO (2007): Promises and Challenges of the Informal Food Sector in Developing Countries.

- (2009): "Good hygienic practices in the preparation and sale of street food in Africa," .

(2013): "Food for the Cities Initiative," .

FAO AND WHO (2002): Global forum of food safety regulators. Marrakesch, Morocco, FAO.

KARLAN, D. AND M. VALDIVIA (2011): "Teaching entrepreneurship: Impact of business training on microfinance clients and institutions," Review of Economics and statistics, 93, 510-527.

Lues, J. F., M. R. Rasephei, P. Venter, And M. M. Theron (2006): "Assessing food safety and associated food handling practices in street food vending," International Journal of Environmental Health Research, 16, 319-328.

Lyon, T. P. AND J. W. MAXWELl (2004): Corporate environmentalism and public policy, Cambridge University Press.

MA, X., S. Sylvia, M. Boswell, AND S. Rozelle (2013): "Ordeal mechanisms and information in the promotion of health goods in Developing Countries:'Evidence from rural China," Rural Education Action Project Working Paper.

Mano, Y., A. IdDrisu, Y. Yoshino, And T. Sonobe (2012): "How can micro and small enterprises in sub-Saharan Africa become more productive? The impacts of experimental basic managerial training," World Development, 40, 458-468.

MAXWEll, J. W., T. P. LYON, AND S. C. HACKetT (2000): "Self-regulation and social welfare: The political economy of corporate environmentalism," The Journal of Law and Economics, 43, 583618.

Mensah, P., D. Yeboah-Manu, K. Owusu-Darko, and A. Ablordey (2002): "Street foods in Accra, Ghana: how safe are they?" Bulletin of the World Health Organization, 80, 546-554.

Meredith, J., J. Robinson, S. WAlKer, AND B. Wydick (2013): "Keeping the doctor away: Experimental evidence on investment in preventative health products," Journal of Development Economics, 105, 196-210.

NCEUS (2007): "Report on conditions of work and promotion of livelihoods in the unorganised sector," National Commission for Enterprises in the Unorganised Sector, Government of India, New Delhi.

(2009): "The Challenge of Employment in India: An Informal Economy Perspective," Report of the National Commission for Enterprises in the Unorganised Sector, Government of India, Volumes, 1. 
NPUSV (2009): "National Policy on Urban Street Vendors," Government of India Ministry of Housing and Urban Poverty Alleviation.

RANE, S. (2011): "Street vended food in developing world: hazard analyses," Indian journal of microbiology, 51, 100-106.

SAHA, D. (2016): Informal Markets, Livelihood and Politics: Street Vendors in Urban India, Routledge.

SAmapundo, S., R. Climat, R. Xhaferi, AND F. Devlieghere (2015): "Food safety knowledge, attitudes and practices of street food vendors and consumers in Port-au-Prince, Haiti," Food control, 50, 457-466.

Samapundo, S., T. C. Thanh, R. Xhaferi, And F. Devlieghere (2016): "Food safety knowledge, attitudes and practices of street food vendors and consumers in Ho Chi Minh city, Vietnam," Food Control, 70, 79-89.

Sigmund, K., C. HAuert, AND M. A. NOWAK (2001): "Reward and punishment," Proceedings of the National Academy of Sciences, 98, 10757-10762.

SoON, J. M., R. BAINeS, AND P. SEAMAN (2012): "Meta-analysis of food safety training on hand hygiene knowledge and attitudes among food handlers," Journal of food protection, 75, 793-804.

VALDIVIA, M. (2015): "Business training plus for female entrepreneurship? Short and medium-term experimental evidence from Peru," Journal of Development Economics, 113, 33-51.

Van Lange, P. A., B. Rockenbach, And T. Yamagishi (2014): Reward and punishment in social dilemmas, Oxford University Press.

WalveKaR, V. (2017): "A Research and Design Initiative for the Informal Sector of Street Food Vending in India," in International Conference on Research into Design, Springer, 309-316.

WHO (2008a): Foodborne disease outbreaks: Guidelines for investigation and control, WHO.

- (2008b): "Foodborne disease outbreaks: guidelines for investigation and control. Geneva: WHO; 2008," .

Wongtada, N. (2014): "Street vending phenomena: A literature review and research agenda," Thunderbird International Business Review, 56, 55-75.

WoRLD BANK (2013): World Bank. 2012. World Development Report 2013: Jobs. Washington, DC: World Bank., World Development Report. 


\section{Appendix}

\section{A.1 Additional results on actual behavior}

Table A.1: Actual Behavior: Diff-in-Diff, split by workshop timing

\begin{tabular}{|c|c|c|c|c|}
\hline & $\begin{array}{c}(1) \\
\text { facilities }\end{array}$ & $\begin{array}{c}\text { (2) } \\
\text { food handling }\end{array}$ & $\begin{array}{c}\text { (3) } \\
\text { customer care }\end{array}$ & $\begin{array}{l}\text { (4) } \\
\text { total }\end{array}$ \\
\hline \multicolumn{5}{|l|}{ Workshop 1} \\
\hline Training (T1 or T2) $\overline{\text { post (within } 1 \text { month) }}$ & $\begin{array}{c}0.090 \\
(0.082)\end{array}$ & $\begin{array}{c}0.028 \\
(0.063)\end{array}$ & $\begin{array}{c}-0.098 \\
(0.091)\end{array}$ & $\begin{array}{l}-0.004 \\
(0.081)\end{array}$ \\
\hline Training (T1 or T2) $\times$ post (within 2 months) & $\begin{array}{l}-0.040 \\
(0.072)\end{array}$ & $\begin{array}{l}-0.029 \\
(0.050)\end{array}$ & $\begin{array}{l}-0.077 \\
(0.084)\end{array}$ & $\begin{array}{l}-0.075 \\
(0.078)\end{array}$ \\
\hline Training (T1 or T2) $\times$ post (within 3 months) & $\begin{array}{l}0.182^{* * *} \\
(0.082)\end{array}$ & $\begin{array}{l}-0.057 \\
(0.054)\end{array}$ & $\begin{array}{c}0.102 \\
(0.095)\end{array}$ & $\begin{array}{c}0.114 \\
(0.077)\end{array}$ \\
\hline Training (T1 or T2) $\times$ post ( 3 months or more) & $\begin{array}{c}0.196 * * * \\
(0.067)\end{array}$ & $\begin{array}{l}-0.037 \\
(0.061)\end{array}$ & $\begin{array}{c}0.066 \\
(0.085)\end{array}$ & $\begin{array}{c}0.097 \\
(0.071)\end{array}$ \\
\hline Training (T1 or T2) & $\begin{array}{c}0.023 \\
(0.068)\end{array}$ & $\begin{array}{c}0.003 \\
(0.050)\end{array}$ & $\begin{array}{c}-0.012 \\
(0.066)\end{array}$ & $\begin{array}{c}0.025 \\
(0.064)\end{array}$ \\
\hline Observations & 3,312 & 2,664 & 3,178 & 3,312 \\
\hline R-squared & 0.186 & 0.181 & 0.353 & 0.251 \\
\hline Workshop 2 & & & & \\
\hline Training (T1 or $\mathrm{T} 2 \overline{2) \times \text { post (within } 1 \text { month) }}$ & $\begin{array}{c}-0.025 \\
(0.066)\end{array}$ & $\begin{array}{c}0.025 \\
(0.053)\end{array}$ & $\begin{array}{l}-0.051 \\
(0.079)\end{array}$ & $\begin{array}{l}-0.038 \\
(0.070)\end{array}$ \\
\hline Training (T1 or T2) $\times$ post (within 2 months) & $\begin{array}{c}0.071 \\
(0.079)\end{array}$ & $\begin{array}{l}-0.053 \\
(0.054)\end{array}$ & $\begin{array}{l}-0.053 \\
(0.084)\end{array}$ & $\begin{array}{l}-0.048 \\
(0.077)\end{array}$ \\
\hline Training (T1 or T2) $\times$ post (within 3 months) & $\begin{array}{c}0.315^{* * *} \\
(0.107)\end{array}$ & $\begin{array}{l}-0.033 \\
(0.073)\end{array}$ & $\begin{array}{c}0.078 \\
(0.098)\end{array}$ & $\begin{array}{l}0.146^{*} \\
(0.079)\end{array}$ \\
\hline Training (T1 or T2) $\times$ post ( 3 months or more) & $\begin{array}{c}0.100 \\
(0.064)\end{array}$ & $\begin{array}{l}-0.025 \\
(0.068)\end{array}$ & $\begin{array}{c}0.079 \\
(0.087)\end{array}$ & $\begin{array}{c}0.078 \\
(0.075)\end{array}$ \\
\hline Training (T1 or T2) & $\begin{array}{c}0.047 \\
(0.066)\end{array}$ & $\begin{array}{c}-0.002 \\
(0.048)\end{array}$ & $\begin{array}{l}-0.016 \\
(0.060)\end{array}$ & $\begin{array}{c}0.033 \\
(0.062)\end{array}$ \\
\hline Observations & 3,312 & 2,664 & 3,178 & 3,312 \\
\hline R-squared & 0.186 & 0.181 & 0.352 & 0.251 \\
\hline \multirow{2}{*}{ Training (T1 or T2) $\frac{\text { Workshop } 3}{\text { post (within } 1 \text { month) }}$} & & & & \\
\hline & $\begin{array}{c}0.054 \\
(0.102)\end{array}$ & $\begin{array}{l}-0.083 \\
(0.057)\end{array}$ & $\begin{array}{l}-0.005 \\
(0.090)\end{array}$ & $\begin{array}{l}-0.040 \\
(0.081)\end{array}$ \\
\hline Training (T1 or T2) $\times$ post (within 2 months) & $\begin{array}{l}0.249 * * * \\
(0.101)\end{array}$ & $\begin{array}{c}0.080 \\
(0.051)\end{array}$ & $\begin{array}{l}-0.111 \\
(0.103)\end{array}$ & $\begin{array}{c}0.070 \\
(0.079)\end{array}$ \\
\hline Training (T1 or T2) $\times$ post (within 3 months) & $\begin{array}{l}-0.057 \\
(0.101)\end{array}$ & $\begin{array}{l}-0.040 \\
(0.081)\end{array}$ & $\begin{array}{l}0.203^{*} \\
(0.114)\end{array}$ & $\begin{array}{c}0.104 \\
(0.108)\end{array}$ \\
\hline Training (T1 or $\mathrm{T} 2) \times$ post ( 3 months or more) & $\begin{array}{l}0.170^{*} \\
(0.086)\end{array}$ & $\begin{array}{l}-0.133 \\
(0.087)\end{array}$ & $\begin{array}{c}0.062 \\
(0.073)\end{array}$ & $\begin{array}{c}0.022 \\
(0.081)\end{array}$ \\
\hline Training (T1 or $\mathrm{T} 2$ ) & $\begin{array}{c}0.056 \\
(0.063)\end{array}$ & $\begin{array}{c}0.005 \\
(0.045)\end{array}$ & $\begin{array}{c}-0.011 \\
(0.050)\end{array}$ & $\begin{array}{c}0.042 \\
(0.055)\end{array}$ \\
\hline Observations & 3,312 & 2,664 & 3,178 & 3,312 \\
\hline R-squared & 0.185 & 0.182 & 0.353 & 0.250 \\
\hline \multicolumn{5}{|c|}{$\begin{array}{l}\text { Notes: The table reports the coefficients for the effects of the training program on vendors' Observed } \\
\text { Behavior. We estimate specification ( } 4 \text { ), which gives us the difference-in-difference estimate of the effect of } \\
\text { training on treatment blocks, comparing their outcomes before and after they have attended the workshops } \\
\text { to those with control blocks at the same point of time. The three panels correspond to the three workshops, } \\
\text { and } \mathrm{T} \times \text { post workshop is an indicator for the vendor being assigned to treatment and monitoring occurring } \\
\text { post the intended (or scheduled) date of each workshop, irrespective of whether they actually attended } \\
\text { (respectively } 1,2,3 \text { or }>3 \text { months after a workshop). All regressions control for vendors' age, gender, } \\
\text { education level, a binary indicator for stall ownership, years vending, area of vending, a binary indicator } \\
\text { for food cooked at the stall, and the type of food, and include interviewer fixed effects. Robust standard } \\
\text { errors, clustered at the block level, are in parentheses. These regressions are estimated using all the } 6 \text { survey } \\
\text { rounds. } * \mathrm{p}<0.10, * * \mathrm{p}<0.05, * * * \mathrm{p}<0.01 \text {. }\end{array}$} \\
\hline
\end{tabular}




\section{A.2 Spillovers and Network Effects}

In this section, we use the information of the networks that the vendors operate in, to explore whether the effects of the training are exacerbated by peer effects. From the location of each block, we know which two blocks are its closest neighbors in terms of geographical distance. We study whether the effect of the training is stronger if at least one of these neighboring blocks is also assigned to treatment, using the triple difference specification

$$
\begin{aligned}
y_{i t} & =\alpha+\beta_{1} T * \text { After } * N_{i t}+\beta_{2} T * N_{i t}+\beta_{3} T * \text { After }_{i t}+\beta_{4} \text { After } * N_{i t}+\beta_{5} T_{i t}+\beta_{6} \text { After }_{i t}+ \\
& +\mathbf{X}_{i t} \gamma+\delta_{t}+\varepsilon_{i t}
\end{aligned}
$$

where $N_{i t}$ is a dummy variable for whether at least one of the two neighboring blocks is treated. If $\beta_{1}$ in this specification is estimated to be stronger than the treatment effects from specifications (3) and (5), it would point towards the presence of peer effects. In a similar vein, we also estimate triple different specifications to examine whether the effect of being a treated vendor post workshop is greater for (i) Being closer to a larger number of treated blocks, and (ii) Being acquainted with a larger number of neighboring vendors.

We proceed in reverse order: first we look at observed behavior, then awareness and claimed behavior. We first test for the simplest kind of peer effect: whether the neighboring vendors' treatment assignment matters. To this end, we estimate specification (A.1), which is a triple difference picking up the effect of being assigned to treatment, having attended all three workshops, plus having at least one of the two neighboring blocks be a treatment block. Panel (A) of Table A.2 reports the results for observed behavior. We see that a neighbor being treated exacerbates the effect of the training for the food handling category by as much as $16 \%$. There is a positive, though insignificant, effect on the other behavioral categories.

Panel (B) and (C) of Table A.2 further explore possible mechanisms for any potential peer effects. One possible explanation is that vendors exchange information with other vendors they know, and if both a vendor and his acquaintances attend the workshops and discuss them, the lessons are reinforced. To check this, we calculate the number of "treated" vendors that each vendor knows, which is simply the sum of the vendors that each vendor knows in his own block and the two neighboring blocks if these blocks are treated. ${ }^{28}$ We then create a binary variable denoting whether

\footnotetext{
${ }^{28} \mathrm{By}$ this measure, not knowing any vendor in one's own block or a neighboring block is observationally equivalent to the same or neighboring
} 
the vendor has more than the median number of treated acquaintances by this definition, which is 8, and re-estimate specification (A.1) replacing the dummy for a treated neighbor with this dummy for knowing more than the median number of treated vendors. The coefficients are reported in Panel (B) of Table A.2. We find no effect on behavior, of being acquainted with a larger number of vendors assigned to training. ${ }^{29}$ Finally, we examine the effect of proximity to a larger number of treated blocks. We calculate the number of blocks assigned to treatment which are within a radius of 1 kilometer from each block. The median number of such blocks is 8 , and we define a similar binary variable denoting whether there are more than 8 blocks ${ }^{30}$ within a kilometer of each block. Then we estimate an identical triple difference specification, this time studying the effect of being a treatment block post training interacted with having a large number of other treated blocks close by. Results are in Panel (C) where, again, we find no significant benefit from being located near a larger density of treated blocks.

Finally, in Tables A.3 and A.4, we replicate this approach focusing on awareness and claimed actions. In the first case, we find that, having a neighboring block be a treatment block, has negligible effect on variables capturing vendors' awareness. ${ }^{31}$ Conversely, we find a substantial spill-over effect when looking at claimed actions. This is true for most of the proxies for claimed actions, suggesting that interactions among vendors might be a powerful channel to spread business related skills in this market.

\footnotetext{
block not being assigned to treatment.

${ }^{29}$ The results are robust to alternative definitions of the cutoff for the dummy, besides the median number of 8 .

${ }^{30} \mathrm{As}$ before, the results are robust to alternative definitions. The results are also robust to restricting the number of "close" blocks to only those which have at least one vendor who sells the same kind of food.

${ }^{31}$ In the table we report only four of the awareness indicators. The results are similar for the remaining not-reported four ones.
} 
Table A.2: Actual Behavior: Spillover and Network Effects

\begin{tabular}{|c|c|c|c|c|}
\hline & (1) & (2) & (3) & (4) \\
\hline & facilities & food handling & customer care & total \\
\hline \multicolumn{5}{|l|}{ Neighboring Block Treated } \\
\hline \multirow[t]{2}{*}{ Training $(\mathrm{T} 1$ or $\mathrm{T} 2) \times$ post $\times$ neighbor $\mathrm{T}$} & 0.004 & $0.042 * *$ & 0.013 & 0.011 \\
\hline & $(0.017)$ & $(0.017)$ & $(0.036)$ & $(0.019)$ \\
\hline \multirow[t]{2}{*}{ Training $(\mathrm{T} 1$ or $\mathrm{T} 2) \times$ post } & $0.036 * *$ & $-0.054 * *$ & 0.014 & 0.018 \\
\hline & $(0.015)$ & $(0.018)$ & $(0.032)$ & $(0.017)$ \\
\hline \multirow[t]{2}{*}{ Training $(\mathrm{T} 1$ or $\mathrm{T} 2) \times$ neighbor } & 0.014 & 0.050 & 0.055 & 0.027 \\
\hline & $(0.024)$ & $(0.034)$ & $(0.040)$ & $(0.029)$ \\
\hline \multirow[t]{2}{*}{ Training (T1 or T2) } & 0.014 & 0.050 & 0.055 & 0.027 \\
\hline & $(0.024)$ & $(0.034)$ & $(0.040)$ & $(0.029)$ \\
\hline \multirow[t]{2}{*}{ Neighbor } & 0.002 & 0.032 & 0.057 & 0.031 \\
\hline & $(0.025)$ & $(0.037)$ & $(0.038)$ & $(0.028)$ \\
\hline Observations & 3,478 & 2,648 & 3,201 & 3,478 \\
\hline \multicolumn{5}{|l|}{ Knowing More Vendors } \\
\hline \multirow[t]{2}{*}{ Training $(\mathrm{T} 1$ or $\mathrm{T} 2) \times$ post $\times$ network } & 0.020 & 0.017 & -0.013 & 0.024 \\
\hline & $(0.014)$ & $(0.014)$ & $(0.042)$ & $(0.014)$ \\
\hline \multirow[t]{2}{*}{ Training $(\mathrm{T} 1$ or $\mathrm{T} 2) \times$ post } & 0.027 & -0.033 & 0.033 & 0.012 \\
\hline & $(0.016)$ & $(0.019)$ & $(0.032)$ & $(0.016)$ \\
\hline \multirow[t]{2}{*}{ Training $(\mathrm{T} 1$ or $\mathrm{T} 2) \times$ network } & -0.029 & -0.007 & 0.036 & -0.019 \\
\hline & $(0.016)$ & $(0.021)$ & $(0.020)$ & $(0.019)$ \\
\hline \multirow[t]{2}{*}{ Training (T1 or $\mathrm{T} 2$ ) } & 0.012 & 0.004 & -0.026 & -0.000 \\
\hline & $(0.009)$ & $(0.024)$ & $(0.029)$ & $(0.017)$ \\
\hline \multirow[t]{2}{*}{ Network } & 0.036 & 0.014 & -0.010 & 0.031 \\
\hline & $(0.020)$ & $(0.016)$ & $(0.036)$ & $(0.024)$ \\
\hline Observations & 3,478 & 2,648 & 3,201 & 3,478 \\
\hline \multicolumn{5}{|l|}{ Close to More Treated Blocks } \\
\hline \multirow[t]{2}{*}{ Training $(\mathrm{T} 1$ or $\mathrm{T} 2) \times$ post $\times$ proximity } & 0.015 & -0.012 & 0.039 & 0.021 \\
\hline & $(0.020)$ & $(0.035)$ & $(0.041)$ & $(0.031)$ \\
\hline \multirow[t]{2}{*}{ Training $(\mathrm{T} 1$ or $\mathrm{T} 2) \times$ post } & 0.029 & -0.014 & -0.004 & 0.013 \\
\hline & $(0.021)$ & $(0.036)$ & $(0.037)$ & $(0.029)$ \\
\hline \multirow[t]{2}{*}{ Training $(\mathrm{T} 1$ or $\mathrm{T} 2) \times$ proximity } & -0.007 & 0.004 & 0.010 & -0.012 \\
\hline & $(0.012)$ & $(0.031)$ & $(0.036)$ & $(0.019)$ \\
\hline \multirow[t]{2}{*}{ Training (T1 or T2) } & 0.010 & 0.001 & -0.011 & 0.005 \\
\hline & $(0.013)$ & $(0.035)$ & $(0.025)$ & $(0.016)$ \\
\hline \multirow[t]{2}{*}{ Proximity } & -0.003 & 0.007 & 0.004 & 0.015 \\
\hline & $(0.012)$ & $(0.024)$ & $(0.041)$ & $(0.015)$ \\
\hline Observations & 3,478 & 2,648 & 3,201 & 3,478 \\
\hline \multicolumn{5}{|c|}{$\begin{array}{l}\text { Notes: The table reports the coefficients for the effects of the training program on vendors' Observed Behavior, depending on vendors } \\
\text { networks. We estimate specification (5), which is a Triple Difference Specification. In panel (A), the triple interaction considers whether } \\
\text { a neighbor block is being treated; in Panel (B), whether a vendor has more than the median number of treated acquaintances; in Panel } \\
\text { (C), whether a vendor has more than the median number of other treated blocks close by. All regressions control for vendors' age, gender, } \\
\text { education level, a binary indicator for stall ownership, years vending, area of vending, a binary indicator for food cooked at the stall, and } \\
\text { the type of food, and include interviewer fixed effects. Robust standard errors, clustered at the block level, are in parentheses. These } \\
\text { regressions are estimated using all the } 6 \text { survey rounds. }{ }^{*} p<0.10,{ }^{* * p} p<0.05,{ }^{* * *} p<0.01 \text {. }\end{array}$} \\
\hline
\end{tabular}


Table A.3: Awareness: Network Effects

\begin{tabular}{|c|c|c|c|c|}
\hline & $\begin{array}{c}(1) \\
\text { Food }\end{array}$ & $\begin{array}{c}(2) \\
\text { Personal }\end{array}$ & $\begin{array}{c}\text { (3) } \\
\text { Contamination }\end{array}$ & $\begin{array}{c}\text { (4) } \\
\text { Utensils }\end{array}$ \\
\hline Training $(\mathrm{T} 1$ or $\mathrm{T} 2) \times$ Treated $\mathrm{Nbr}$ & $\begin{array}{c}0.031 \\
(0.059)\end{array}$ & $\begin{array}{l}0.060 * \\
(0.033)\end{array}$ & $\begin{array}{c}0.039 \\
(0.081)\end{array}$ & $\begin{array}{c}0.050 \\
(0.071)\end{array}$ \\
\hline Training (T1 or T2) & $\begin{array}{c}0.054 \\
(0.051)\end{array}$ & $\begin{array}{c}-0.020 \\
(0.022)\end{array}$ & $\begin{array}{c}0.038 \\
(0.060)\end{array}$ & $\begin{array}{c}0.054 \\
(0.054)\end{array}$ \\
\hline Treated Nbr & $\begin{array}{l}-0.071 \\
(0.055)\end{array}$ & $\begin{array}{c}-0.045 * * \\
(0.022)\end{array}$ & $\begin{array}{l}-0.140 * \\
(0.072)\end{array}$ & $\begin{array}{c}-0.084 \\
(0.068)\end{array}$ \\
\hline Observations & 561 & 561 & 561 & 561 \\
\hline R-squared & 0.572 & 0.783 & 0.412 & 0.301 \\
\hline
\end{tabular}

Notes: The table reports the coefficients for the effects of the training program on vendors' Awareness, depending on vendors' networks. The interaction considers whether a neighbor block is being treated. All regressions control for vendors' age, gender, education level, a binary indicator for stall ownership, years vending, area of vending, a binary indicator for food cooked at the stall, and the type of food, and include interviewer fixed effects. Robust standard errors, clustered at the block level, are in parentheses. " $\mathrm{p}<0.10,{ }^{* *} \mathrm{p}<0.05, \stackrel{* * *}{*} \mathrm{p}<0.01$. 


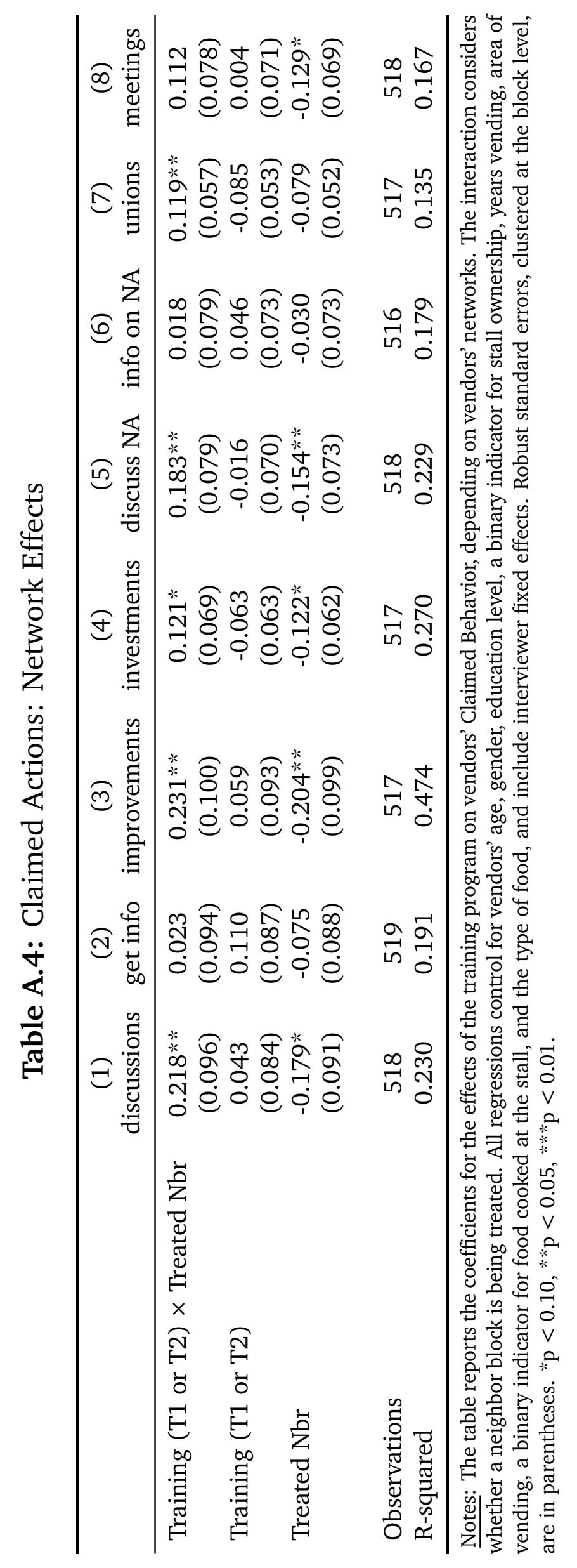




\section{A.3 Additional results on the mechanisms}

Table A.5: Comparing T1 with T2

\begin{tabular}{|c|c|c|c|c|}
\hline & (1) & (2) & (3) & (4) \\
\hline & \multicolumn{4}{|c|}{ Panel A: Awareness } \\
\hline & food & personal & contamination & utensils \\
\hline Training (T1) & $\begin{array}{c}-0.209 * * * \\
(0.053)\end{array}$ & $\begin{array}{c}-0.083 \\
(0.054)\end{array}$ & $\begin{array}{c}-0.018 \\
(0.079)\end{array}$ & $\begin{array}{l}-0.078^{*} \\
(0.046)\end{array}$ \\
\hline Observations & 341 & 341 & 341 & 341 \\
\hline \multirow[t]{2}{*}{ R-squared } & 0.624 & 0.739 & 0.416 & 0.343 \\
\hline & \multicolumn{4}{|c|}{ Panel B: Claimed Actions } \\
\hline Training (T1) & $\begin{array}{c}-0.036 \\
(0.097)\end{array}$ & $\begin{array}{l}-0.008 \\
(0.080)\end{array}$ & $\begin{array}{l}-0.079 \\
(0.102)\end{array}$ & $\begin{array}{l}0.098 * * \\
(0.046)\end{array}$ \\
\hline Observations & 329 & 329 & 327 & 328 \\
\hline \multirow[t]{3}{*}{ R-squared } & 0.202 & 0.197 & 0.420 & 0.291 \\
\hline & \multicolumn{4}{|c|}{ Panel C: Behavior } \\
\hline & facilities & food handling & customer care & total \\
\hline Training (T1) & $\begin{array}{c}0.022 \\
(0.022)\end{array}$ & $\begin{array}{l}0.029 * * \\
(0.014)\end{array}$ & $\begin{array}{c}0.013 \\
(0.019)\end{array}$ & $\begin{array}{l}0.037^{*} \\
(0.019)\end{array}$ \\
\hline Observations & 2,142 & 1,606 & 1,958 & 2,142 \\
\hline R-squared & 0.179 & 0.240 & 0.365 & 0.248 \\
\hline
\end{tabular}

Notes: The table reports the coefficients for the effects of the training program on all our outcomes (Awareness, Claimed Behaviour and Behaviour) restricting the sample to the treated vendors, therefore comparing vendors in $\mathrm{T} 1$ with vendors in $\mathrm{T} 2$ (similarly to specification (1)). In this case we also control for the amount of time elapsed since the vendor had their first workshop. All regressions control for vendors' age, gender, education level, a binary indicator for stall ownership, years vending, area of vending, a binary indicator for food cooked at the stall, and the type of food, and include interviewer fixed effects. Robust standard errors, clustered at the block level, are in parentheses. ${ }^{*} \mathrm{p}<0.10{ }^{* * *} \mathrm{p}<0.05,{ }^{* * *} \mathrm{p}<0.01$. 